\title{
Skeletal Muscle Vascular Function: A Counterbalance of Insulin Action
}

\author{
Abeer M. Mahmoud ${ }^{1,3}$, Michael D. Brown ${ }^{1,3}$, Shane A. Phillips ${ }^{2,3}$, Jacob M. Haus ${ }^{1,3}$ \\ ${ }^{1}$ Department of Kinesiology and Nutrition, University of Illinois at Chicago, Chicago, Illinois \\ ${ }^{2}$ Department of Physical Therapy, University of Illinois at Chicago, Chicago, Illinois \\ ${ }^{3}$ Integrative Physiology Laboratory, College of Applied Health Sciences, University of Illinois at \\ Chicago, Chicago, Illinois
}

Running Title: Vascular Dysfunction in Hyperinsulinemia

Corresponding Author:
Jacob M. Haus, Ph.D.

University of Illinois at Chicago

1919 W. Taylor St, Rm 650

Chicago, IL 60612-7256

Ph: (312) 413-1913

Fx: (312) 413-0319

E-mail: hausj@uic.edu 


\section{TABLE OF CONTENTS}

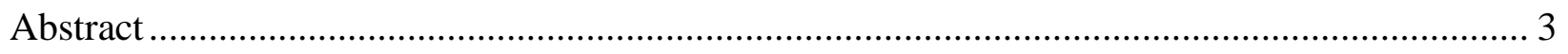

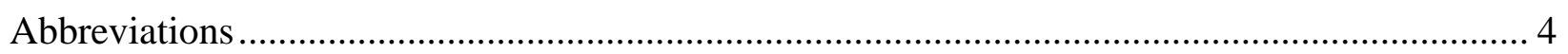

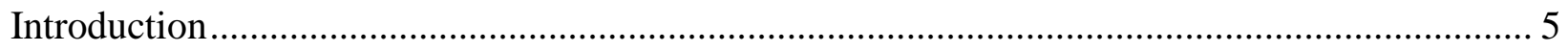

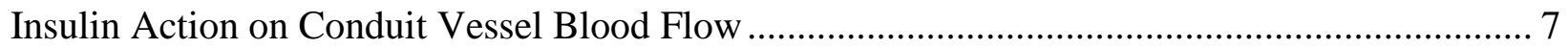

Effect on Lean, Healthy Individuals ………………….................................................... 7

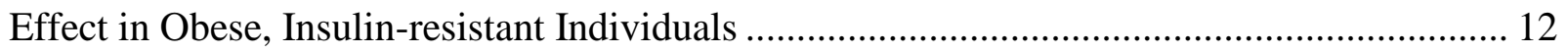

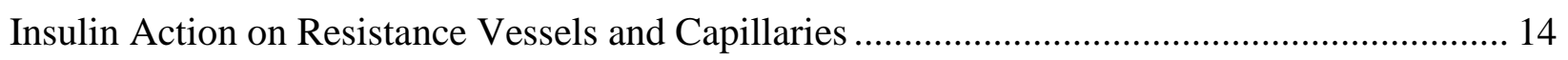

Effect on Lean, Healthy Individuals ............................................................................... 14

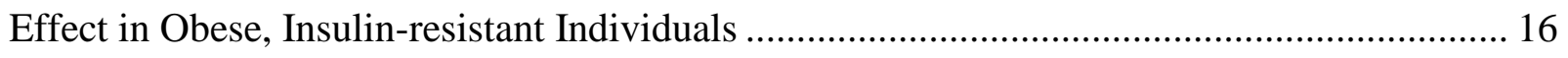

Vascular Action of Hyperinsulinemia in Animal Models .......................................................... 18

Cellular Events Responsible For Insulin-mediated Vascular Action .......................................... 19

Insulin Signaling in Vascular Endothelium - Vasodilation..................................................... 21

Insulin Signaling in Vascular Endothelium - Vasoconstriction ............................................. 23

Hyperinsulinemia and Vascular Homeostasis .................................................................... 26

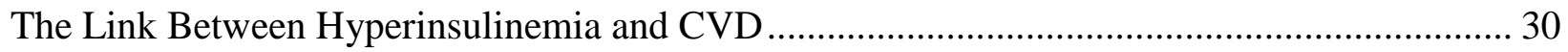

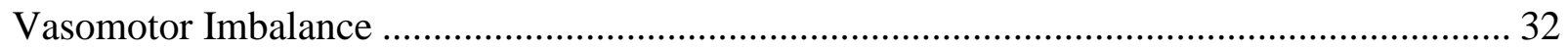

Inflammation and Oxidative Stress ................................................................................ 33

Advanced Glycation End-products (AGEs) ..................................................................... 34

Matrix Remodeling and Arterial Stiffness ......................................................................... 34

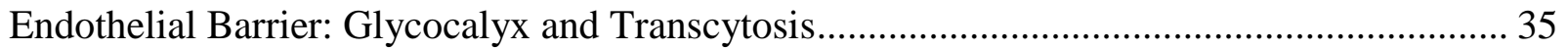

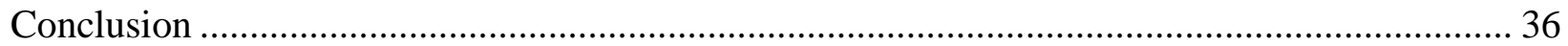

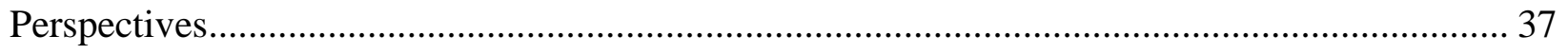

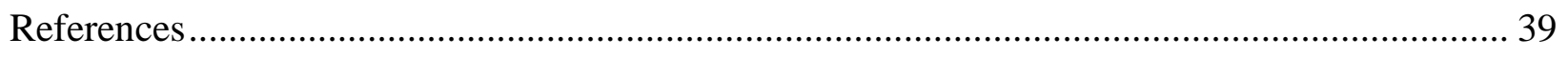

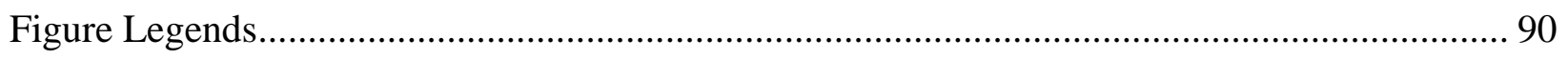

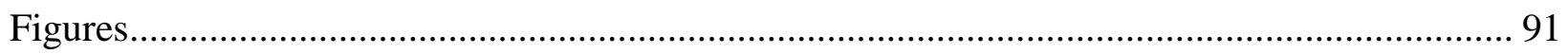




\section{ABSTRACT}

Insulin is a vasoactive hormone that regulates vascular homeostasis by maintaining balance of endothelial derived nitric oxide (NO) and the potent vasoconstrictor, endothein-1 (ET-1). Although there is general agreement that insulin resistance and the associated compensatory hyperinsulinemia disturb this balance, the vascular consequences for hyperinsulinemia in isolation from insulin resistance are still unclear. Presently, there is no simple answer for this question, especially in a background of mixed reports examining the effects of experimental hyperinsulinemia on endothelial mediated vasodilation. There is also a lack of consistency between clinical and mechanistic studies in regards to the vascular outcomes of hyperinsulinemia. Understanding the mechanisms by which hyperinsulinemia induces vascular dysfunction is essential in advancing treatment and prevention of obesity and insulin resistance-related vascular complications. Thus, herein, we review key human and animal literature addressing the effects of hyperinsulinemia on vascular function, at both the clinical and cellular levels. Further, we give special attention to the vasoregulatory effects of hyperinsulinemia on skeletal muscle, the largest insulin-dependent organ in the body. This review will also characterize the differential vascular effects of hyperinsulinemia on large conduit vessels versus small resistance microvessels and the dramatic effects of key experimental variables such as insulin dose, duration of exposure, and underlying insulin sensitivity in an effort to unravel potential sources of discrepancies in the literature. At the cellular level, we provide an overview of insulin signaling events governing vascular tone. Finally, we hypothesize a role for hyperinsulinemia and insulin resistance in the development of cardiovascular disease (CVD).

Keywords: insulin resistance; hyperinsulinemia; skeletal muscle; vascular dysfunction. 


\section{ABBREVIATIONS}

AGEs, advanced glycation end products; AKT, protein kinase B; ATPase, adenosine triphosphatase; BH4, tetrahydrobiopterin; BMI, body mass index; CEU, contrast enhanced ultrasound; CRP, C-reactive protein; CVD, cardiovascular disease; ECE, endothelial converting enzyme; eNOS, endothelial nitric oxide synthase; ERK, extracellular signal-regulated kinase; ET1, endothelin-1; $\mathrm{ET}_{\mathrm{A}}$, endothelin-1 receptor type $\mathrm{A} ; \mathrm{ET}_{\mathrm{B}}$, endothelin-1 receptor type $\mathrm{B} ; \mathrm{FAD}$, flavin adenine dinucleotide; FBF, forearm blood flow; FMN, flavin mononucleotide; GLUT-1, glucose transferase-1; GLUT-4, glucose transferase-4; GDP, guanosine diphosphate; GMP, guanosine monophosphate; GTP, guanosine triphosphate; HMGB1, high-mobility group protein B1; HOMA-IR, homeostasis model assessment of insulin resistance; HUVEC, human umbilical vein endothelial cell; ICAM-1, intracellular adhesion molecule-1; ICG, indocyanine green; IDM, indicator dilution method; IFN- $\gamma$, interferon gamma; IGF, insulin growth factor receptor; IL, interleukin; IP3, inositol triphosphate; IRS-1, insulin receptor substrate-1; LBF, leg blood flow; LDL, low-density lipoproteins; LDU, laser Doppler ultrasound; LHC, lean healthy controls; LNAME, NG-monomethyl-L-arginine; MAPK, mitogen activated protein kinase; MBF, microvascular blood flow; MBV, microvascular blood volume; MEK, mitogen activated protein kinase kinase; MFV, microvascular flow velocity; MG, methylglyoxal; MnSOD, manganese superoxide dismutase; NADPH, Nicotinamide adenine dinucleotide phosphate; NFkB, nuclear factor kappa-light-chain-enhancer of activated B cells; NO, nitric oxide; NOS, nitric oxide synthase; OB/IR, obese insulin resistant; PDK-1, phosphoinositide-dependent kinase-1; PET, positron emission tomography; PI3K, phosphatidylinositol 3 kinase; PIP2, phosphatidylinositol 4,5-bisphosphate; PKC, protein kinase C; PLC, phospholipase C; RAF, rapidly accelerated fibrosarcoma; RAGE, receptor of advanced glycation end products; RAS, rat sarcoma; ROS, reactive oxygen species; SGP, strain gauge plethysmography; SOS, son of sevenless; T2DM, type 2 diabetes mellitus; TNF- $\alpha$, tumor necrosis factor alpha; VCAM-1, vascular cell adhesion molecule-1; VUS, vascular ultrasound. 


\section{INTRODUCTION}

Insulin is a metabolic hormone that also plays a central role as a vasoactive mediator, a function that is critical for insulin mediated glucose uptake and disposal. Traditionally, insulin induces relaxation of the large conduit vessels leading to an overall increase in blood flow [13]. In addition, terminal arterioles and capillaries respond to the vasodilatory effects of insulin, resulting in a greater microvascular perfusion [50,241]. Figure 1 illustrates the known physiological actions of insulin at different sites in the peripheral vascular tree of skeletal muscle. The functional connection between insulin-mediated glucose uptake and insulin-mediated vasodilation has become increasingly evident over the past several years. Adequate tissue vascularity and nutrient exposure are required for proper glucose metabolism. Of all the different tissue types, skeletal muscle is the most critical in glucose metabolism since it accounts for more than $80 \%$ of insulinstimulated glucose disposal [58]. In addition, skeletal muscle insulin resistance is the primary defect in the development of type 2 diabetes (T2DM) and future risk of cardiovascular disease (CVD). Skeletal muscle permeability to glucose is high, thus blood flow (substrate delivery) is expected to act as a rate limiting step for glucose uptake [92]. Numerous studies have demonstrated a positive correlation between insulin-stimulated leg blood flow and leg muscle glucose uptake across a broad range of insulin sensitivity in healthy adults $[17,169,170,221,245]$.

However, in insulin resistant individuals, this relationship is not overly apparent and increasing limb blood flow during a hyperinsulinemic-euglycemic clamp is not always associated with increased skeletal muscle glucose uptake $[113,148,155]$. These observations argue the notion that the metabolic and vascular actions of insulin may be incongruent in individuals with insulin resistance. Interestingly, Solomon et al. [202] demonstrated that skeletal muscle capillary density, as well as plasma NO levels, were markedly reduced across the glucose tolerance continuum and 
correlated significantly with the degree of insulin sensitivity. These findings suggest that skeletal muscle insulin resistance plays a critical role in diminished vascularity and/or impaired vascular action and subsequently, reduced nutrient exposure.

At physiological levels, insulin regulates vascular homeostasis by maintaining the balance of endothelial derived vasodilators (mainly, nitric oxide (NO)) and vasoconstrictors (e.g. endothelin-1 (ET-1)) [144]. In skeletal muscle tissue, insulin mediated vasodilation of resistance vessels increases access to nutritive capillary beds that are receiving little or intermittent flow in the basal state [44]. Thus, disturbance in insulin action impairs skeletal muscle perfusion and functional capacity leading to reduced physical activity, sedentary lifestyle, and increased risk for developing CVD [1]. Despite the established vasodilatory action of insulin, hyperinsulinemia can lead to vascular dysfunction and induce insulin resistance-related pathogenesis [129]. Yet, studies that use experimental hyperinsulinemia to examine the vascular actions of insulin have shown inconsistent findings. Some of these studies reported enhanced limb blood flow in response to insulin stimulation [47,65,76,203], while others demonstrated either null effects or reduction in blood flow $[10,88,141,229]$. As a result, the prevailing concept that hyperinsulinemia induces vasodilation and improves blood flow may need to be reconsidered. Also, studies that demonstrated contradictory results for hyperinsulinemia-induced vascular actions need to be scrutinized for variables that might have contributed to this controversy.

This discrepancy in the literature could be attributed to a lack of mechanistic separation of impaired insulin action versus the resultant compensatory hyperinsulinemia on endothelialdependent vasodilation. It may also be explained by the heterogeneity in insulin doses and duration of insulin exposure among studies that have examined insulin's vascular action (Table 1). Lack of consensus could also be attributed to the reliance on concentrations of circulating biomarkers, such 
as ET-1, to predict insulin's vasoconstrictor effects, ignoring the fact that ET-1 acts predominantly in local fashion after being released from endothelial cells [246]. Still, the vascular action of insulin can be modified by other co-existing factors such as hyperglycemia, hyperlipidemia, inflammation, and elevated oxidative stress $[90,186]$. The lack of precise understanding of these mechanisms has delayed the progress in the prevention and treatment of insulin resistance related cardiometabolic syndrome and CVD. The aim of this review is to examine the current state of the literature on skeletal muscle blood flow (large, conduit vessels) and microvascular response to hyperinsulinemia among lean healthy and insulin-resistant individuals. This analysis was conducted in the context of varying exposure to insulin doses and durations used in these studies in an effort to elucidate the discrepancies and ambiguity surrounding insulin's vascular action.

\section{INSULIN ACTION ON CONDUIT VESSEL BLOOD FLOW}

\section{Effect on Lean, Healthy Individuals}

It has been conclusively established that there is a very close relationship between the metabolic and vascular actions of insulin in skeletal muscle. However, studies that have examined the blood flow response to insulin infusion have not consistently identified insulin-induced vasodilation. The most striking observation was the large heterogeneity of insulin doses used in these studies. Herein, we summarized the outcome from select studies that have examined blood flow in limb conduit vessels during a hyperinsulinemic-euglycemic clamp in healthy individuals using a variety of hemodynamic approaches (Table 1). The hyperinsulinemic-euglycemic clamp is the gold standard technique for measuring insulin sensitivity and studying the effects of an acute insulin response in vivo. The goal of the hyperinsulinemic-euglycemic clamp is to acutely raise, and maintain, desired steady state plasma insulin concentrations, while simultaneously maintaining euglycemia at $\sim 90$ $\mathrm{mg} / \mathrm{dl}(5 \mathrm{mM})$ through a variable rate glucose infusion $[9,59]$. The amount of glucose required 
(glucose infusion rate) to maintain euglycemia is equal to disposal of glucose (rate of glucose disposal) into insulin sensitive tissues, thus glucose infusion rate is a measure of insulin sensitivity. The most commonly applied insulin infusion rate of the hyperinsulinemic-euglycemic clamp is 40 $\mathrm{mU}$ insulin per square meter body surface per minute $\left(40 \mathrm{mU} / \mathrm{m}^{2} / \mathrm{min}\right)$, which has been reported to correspond to approximately $1 \mathrm{mU}$ insulin per kilogram body weight per minute $(1 \mathrm{mU} / \mathrm{kg} / \mathrm{min})$ [176]. These infusion rates yield a range of physiological peripheral hyperinsulinemia in a $70 \mathrm{~kg}$ individual (50 - $130 \mu \mathrm{U} / \mathrm{mL}$ or $347-903 \mathrm{pmol} / \mathrm{L}$ ) that generally correspond to peripheral insulin concentrations after meal ingestion [24,107,176,199].

Since the original clamp experiments, numerous infusion rates and body size normalization variations exist in the literature. Although most studies have uniformly applied insulin doses during the euglycemic clamp, steady state plasma insulin concentrations display wide variability in the literature $(\sim 70-132 \mu \mathrm{U} / \mathrm{mL}$ during $1 \mathrm{mU} / \mathrm{kg} / \mathrm{min}$ insulin infusion) $[57,59,176]$. These differences are likely due to numerous factors such as differences in insulin assay and individual metabolic differences in hepatic insulin clearance, fasting plasma insulin and insulin suppression of endogenous glucose production [176]. For ease of interpretation and study comparison, we have converted all insulin infusion rates into $\mathrm{mU} / \mathrm{kg} / \mathrm{min}$ using the conversion referenced above. For additional reference, normal fasting insulin levels range from 5 - $20 \mu \mathrm{U} / \mathrm{ml}(35$ - 139 pmol/L) [43], while postprandial insulin can reach $\geq 150 \mu \mathrm{U} / \mathrm{ml}(1042 \mathrm{pmol} / \mathrm{L})$ [9].

Table 1 shows that, in most studies, insulin infusions of $1.0-1.6 \mathrm{mU} / \mathrm{kg} / \mathrm{min}$ were performed. However, in some studies, higher insulin doses of $32.2 \mathrm{mU} / \mathrm{kg} / \mathrm{min}[15,28,76]$ or lower doses (as low as $0.05 \mathrm{mU} / \mathrm{kg} / \mathrm{min}$ ) have been used [10,50,76,141,158,229]. Still, other studies have performed insulin dose-response curves of $20-1200 \mathrm{mU} / \mathrm{m}^{2} / \mathrm{min}(0.5-32.2 \mathrm{mU} / \mathrm{kg} / \mathrm{min})[110,111]$. In order to better understand the role of insulin dose on the regulation of blood flow in large conduit 
vessels, we stratified insulin doses used in the studies we examined into 3 categories: low doses ( $<0.5 \mathrm{mU} / \mathrm{kg} / \mathrm{min})$, moderate doses $(0.5-2 \mathrm{mU} / \mathrm{kg} / \mathrm{min})$, and high doses ( $>2 \mathrm{mU} / \mathrm{kg} / \mathrm{min})$.

All of the studies that used high doses of insulin (> $2 \mathrm{mU} / \mathrm{kg} / \mathrm{min})$ reported increases in limb blood flow of healthy individuals $[15,28,111,120,143,201]$. The observed increases in limb blood flow were confirmed by using both non-invasive and invasive measurement techniques, such as, strain gauge plethysmography (SGP) or vascular ultrasound (VUS), and the indicator dilution method (IDM) thermodilution or indocyanine green (ICG), respectively. The time-course of insulin-stimulated muscle blood flow showed increases throughout the infusion period $[111,192,201]$. These data also indicate an apparent plateau effect (maximal dilation) within $2 \mathrm{hrs}$. The time needed to reach the plateau effect was similar when different doses were used. However, the experimental approach in these studies did not allow for analysis of dose $\mathrm{x}$ time interactions on insulin-induced vasodilation. Interestingly, studies using moderate insulin doses (0.5-2 $\mathrm{mU} / \mathrm{kg} / \mathrm{min}$ ) had inconsistent findings in lean, healthy individuals. In some of these studies, increased blood flow was observed. For instance, Eggleston et al. [65] demonstrated a gradual increase in forearm blood flow that only became apparent after 100 min of moderate dose insulin infusion (1 mU/kg/min). Using the same insulin infusion rate, Clerk et al. [47] observed marked increases in brachial artery diameter, blood flow and flow velocity at the end of a $2 \mathrm{hr}$ hyperinsulinemic-euglycemic clamp, and Sonne et al. [203] reported significant increases in total forearm blood flow. Comparable findings were noted in response to insulin infusion rates of $\sim 1.5-$ $1.6 \mathrm{mU} / \mathrm{kg} / \mathrm{min}[88,178,221]$. Similar to the high doses, moderate doses of insulin also caused stepwise increases in limb blood flow, and the maximum flow rate was reached within $\sim 2 \mathrm{hrs}$ of infusion with minimal responses afterwards [178]. However, improved blood flow was not detected in studies using moderate insulin doses lasting greater than $2 \mathrm{hrs}[28,65,88,156]$. Although 
advanced age and borderline body mass index (BMI) may explain the modest effects reported by Hedman [88], null effects have also been observed in young and middle-aged individuals who were lean and healthy $[28,65,156]$.

The lack of homogenous response is also apparent in studies utilizing low dose insulin. Increased limb blood flow has been shown in response to insulin infusion at rates of 0.06 to 0.5 $\mathrm{mU} / \mathrm{kg} / \mathrm{min}[50,76,111]$, whereas other studies have reported null effects in healthy, young men at similar insulin infusion rates [141,158,229]. These conflicting data are further complicated by additional studies demonstrating blood flow reductions in response to low $(0.2 \mathrm{mU} / \mathrm{kg} / \mathrm{min})$ or moderate $(0.9 \mathrm{mU} / \mathrm{kg} / \mathrm{min})$ hyperinsulinemia [10]. It is important to note that the latter study had the longest duration of insulin infusion (6 hrs), with the other studies ranging from 2-4 hrs (Table 1). This might suggest that the longer duration of insulin exposure had a deleterious effect. However, further investigations are required to support this hypothesis.

Collectively, there is a large degree of variability regarding the effect of hyperinsulinemia on limb conduit vessel blood flow. While high insulin doses ensured increases in limb blood flow of healthy individuals, a physiological range of insulin doses has yielded mixed results. This variability suggests that additional, more complex factors govern insulin-induced vasodilation. Such factors may include glucose, lipids, and glucose counter-regulatory hormones, as well as underlying morbidities, or other more basic subject characteristics, such as age, race, or body composition [154,167,210,233].

Among these factors, glycemia may have great influence on blood flow. Both hypoglycemia and hyperglycemia have been independently reported to induce changes in blood flow. Previous studies have suggested that hypoglycemia may induce vasodilation via the release of epinephrine [60]. Conversely, hyperglycemia has been linked to vasoconstriction through 
several mechanisms, such as the generation of the endothelium-derived vasoconstrictors (prostanoids [225] and ET-1 [150]), reduction in NO production [79], induction of oxidative stress [226], and the formation of advanced glycation end products (AGEs) [53]. However, other studies have demonstrated enhanced blood flow in response to either local or systemic hyperglycemia. For instance, Van Gurp et al. [235] showed sustained hyperglycemia (20mmol/L or $360 \mathrm{mg} / \mathrm{dL})$ for $6 \mathrm{hrs}$ increased forearm blood flow and reduced vascular resistance in lean, healthy individuals. Studies that investigated the combined effect of hyperinsulinemia and hyperglycemia using a hyperinsulinemic-hyperglycemic clamp have shown that hyperinsulinemia, when applied concomitantly with hyperglycemia, attenuates the significant vasodilatory effect achieved by hyperglycemia alone [62]. Similar findings have been reported by studies that examined the effect of acute local hyperglycemia, with and without local hyperinsulinemia, on the forearm vascular tone [236]. In addition, hyperglycemia accompanied by physiological hyperinsulinemia achieved via the $2 \mathrm{hr}$ oral glucose-tolerance test, resulted in increased limb blood flow and reduced vascular resistance $[64,119]$. Despite the contradictions concerning whether hyperglycemia induces vasoconstriction or vasodilation, these studies establish the concept that blood glucose alone impacts vascular dynamics and could act as a confounder for insulin regulation of blood flow.

Further, one cannot ignore the hemodynamic approach and the variable sensitivity among these approaches. The studies highlighted above used three main techniques to measure blood flow in conduit vessels: 1) VUS, 2) SGP, and 3) IDM (thermodilution and ICG green dye infusion). Another approach that has been used less frequently due its high cost and limited availability is positron emission tomography (PET). PET allows direct quantification of the regional blood flow with high temporal and spatial resolution [168]. Using this unique hemodynamic approach, three studies have reported significant increases in total leg blood flow/volume [112,170,234]. However, 
high insulin doses $(5 \mathrm{mU} / \mathrm{kg} / \mathrm{min})$ were used in these studies, which makes it difficult to discern whether the frequently-reported increase in total leg blood flow is attributable to the sensitivity of PET or the use of high doses of insulin.

All the techniques mentioned above have certain limitations. These concerns have been comprehensively reviewed elsewhere [20]. The inconsistent findings among studies that measured insulin-stimulated blood flow were not limited to a single technique, and variability was evident across the three different methods. These observations might exclude the hemodynamic approach as a primary source of discrepancy among studies in which insulin-mediated changes in limb blood flow were measured. Certainly, further study in this area is warranted to elucidate the underlying mechanisms.

\section{Effect in Obese, Insulin-resistant Individuals}

There is strong evidence that supports the presence of insulin resistance as a major pathology in metabolic disorders, such as obesity and T2DM [121]. Insulin resistance is characterized by an impairment of insulin action in insulin sensitive tissues, such as skeletal muscle, adipose tissue, and liver. Since skeletal muscle is the primary site for glucose metabolism and is responsible for more than $80 \%$ of insulin-stimulated glucose uptake, skeletal muscle insulin resistance is considered to be the primary defect in the development of T2DM [3]. In healthy humans, postprandial, physiological hyperinsulinemia stimulates blood flow to the skeletal muscle and, as a result, glucose delivery and metabolism. However, in subjects who are insulin resistant or have T2DM, the ability of insulin to induce blood flow is impaired. It is still unclear if insulin resistance is a cause or a consequence of this impairment [110,111,244]. The association between these metabolic disorders and vascular dysfunction is complex and can be confounded by many factors, including hyperglycemia, dyslipidemia, inflammation, and oxidative stress [224]. However, when 
insulin resistance accompanies these metabolic disorders, vascular dysfunction related to the impaired insulin action, as well as the associated hyperinsulinemia, should be considered [174]. In support of this conclusion, Natali et al. [149] showed the percentage increase in blood flow after insulin infusion was progressively attenuated with increasing insulin resistance. We summarized studies that have reported blood flow responses to experimental hyperinsulinemia in obese and/or T2DM individuals in whom insulin resistance was characterized (Table 2). Similar to Table 1, we stratified insulin dose into low, moderate, and high categories, however the original reported infusion rates are presented because the majority of studies scaled their infusion rates to body surface area $\left(\mathrm{BSA}\right.$ in $\left.\mathrm{m}^{2}\right)$. When data were available, we calculated BSA using the method of DuBois [61] to confirm dose stratification.

A uniform observation was that insulin-stimulated blood flow in the conduit vessels of T2DM subjects was impaired across all insulin doses, independent of age or BMI. However, in obese, non-diabetic subjects, results were contradictory related to insulin action on conduit vessel blood flow. A number of studies showed increased blood flow in response to moderate [110] and high insulin doses [110,120,143], while others have reported null effects $[47,175,201,221]$. Interestingly, all the studies that reported null effects measured blood flow in the forearm, while three of the four studies that demonstrated increased blood flow, performed the measurement in the leg (Table 2). This might indicate inherent differences in the response to insulin between forearm and leg tissues. In support of this assumption, Oslen et al. [158] showed baseline blood flow in the arms of T2DM subjects was significantly greater than in their legs, which may preclude the demonstration of any additional vasodilation in the conduit blood vessels of the arm during insulin infusion; however, we are not aware of direct comparisons per unit muscle mass and further studies are needed to support this presumption. 
One may be tempted to assume that chronic hyperinsulinemia in obese, insulin-resistant or diabetic subjects might cause a persistent, maximum vasodilation that reduces the chance for further vasodilation during the insulin clamp; however, several studies that examined baseline blood flow in conduit vessels showed markedly lower results in obese, insulin-resistant and T2DM subjects relative to lean, healthy individuals $[47,158,201,221]$. Furthermore, the insulin dose and duration of exposure required to induce vasodilation in obese, insulin-resistant subjects were much higher than in lean, healthy controls. Laakso et al. [111] showed that, in order to increase insulinstimulated leg blood flow in obese, insulin-resistant subjects to levels comparable to age-matched lean, healthy controls, four-fold higher doses of insulin were required. Similarly, Sjostrand et al. reported delayed onset of insulin action on blood flow in obese, insulin-resistant subjects relative to lean, healthy controls [201]. Also, in obese and T2DM subjects, the ability of insulin to potentiate the action of other cholinergic vasodilators, such as acetylcholine and methacholine chloride, was severely impaired relative to healthy individuals $[189,209]$. Overall, there is agreement in the current literature that insulin-stimulated blood flow in conduit vessels is diminished in metabolic disorders that are characterized by the presence of insulin resistance, and that higher supra-physiological doses of insulin may succeed in inducing blood flow in some, but not all, individuals with insulin resistance.

\section{INSULIN ACTION ON RESISTANCE VESSELS AND CAPILLARIES}

\section{Effect on Lean, Healthy Individuals}

Beyond the vascular action of insulin on conduit vessel blood flow, there is a vascular response by resistance vessels that results in enhancement of microvascular blood volume and capillary recruitment in skeletal muscle. This part of insulin action expands the surface area of skeletal muscle that is accessible to insulin and nutrient delivery [48,50,173]. Assessment of microvascular 
insulin action in human skeletal muscle has been performed by several studies using contrastenhanced ultrasound (CEU) to analyze one or more of the following measurements: microvascular blood volume (MBV), microvascular blood flow (MBF), and microvascular flow velocity (MFV). Correlations between these measurements and the rate of glucose uptake have been previously established, further emphasizing the importance of insulin in regulating local blood flow [18]. Table 3 summarizes the methods and outcomes from select studies that examined the effects of experimental hyperinsulinemia on skeletal muscle microvasculature in healthy and insulinresistant individuals. There seems to be general agreement among these studies that all dosage levels of insulin enhance MBV in healthy young individuals. However, Timmerman et al. [229] demonstrated no increase in leg MBV in response to low hyperinsulinemia $(0.19 \mathrm{mU} / \mathrm{kg} / \mathrm{min})$. The subjects in this study had an average age of $71 \mathrm{yrs}$, which could explain the diminished response to insulin, since increased age is known to be associated with reduced insulin sensitivity [183]. Insulin-stimulated MBF was also consistently increased in skeletal muscle of lean, healthy individuals [117,187,217]. Nevertheless, a paradoxical reduction in MFV was shown by Coggins et al. [50] in response to low doses of insulin $(0.05-0.1 \mathrm{mU} / \mathrm{kg} / \mathrm{min})$, which is difficult to explain, especially with a concomitant increase in MBV. Unpredictably, most of the studies that demonstrated increases in MBV also reported null response or decrease in MFV after 1-3 hrs of sustained low-to-moderate $[36,47,117,135,187,200]$ hyperinsulinemia. However, higher doses of insulin increased MFV significantly [143], which might indicate that insulin-stimulated MFV in skeletal muscle of lean, healthy individuals is dose-dependent.

More consistent results have been obtained in studies concerning the effects of insulin on MBV and MBF in lean, healthy individuals compared to blood flow in conduit vessels. In some studies, the low insulin doses $(0.05 \mathrm{mU} / \mathrm{kg} / \mathrm{min})$ that significantly enhanced microvascular blood 
volume in skeletal muscle did not improve conduit vessel blood flow during the hyperinsulinemiceuglycemic clamp procedure [50,145]. Also, Eggleston et al. [65] reported an increase in skeletal muscle MBV within 20 min of insulin infusion, and this observation preceded increases in total blood flow that were observed only after $100 \mathrm{~min}$. This dissociation between the microvascular and conduit vessel blood flow response could be attributed to the higher sensitivity and the faster hemodynamic reactions of the terminal resistance arterioles that control capillary recruitment and perfusion. Insulin-induced changes in conduit vessel blood flow appear to be more time-dependent and dose-dependent than changes in microvessels. As mentioned above, the hemodynamic approach is an important consideration that contributed to the homogeneity of the results. Apart from the study of Murdolo [145] in which muscle microdialysis was used, the remaining studies measuring MBV in skeletal muscle using CEU. Currently, there are only a few established techniques for measuring microvascular perfusion in skeletal muscle, such as CEU with gas-filled microbubbles [50], microdialysis [151], and metabolism of 1-methylxanthine (an exogenouslyadded substrate for capillary xanthine oxidase) [173]. For more information on these techniques, the reader is directed to a review by Barrett and Rattigan [20], which discusses the strengths and limitations of the most commonly-used methods to measure blood flow and microvascular perfusion in skeletal muscle. Since direct measurement of the muscle microvascular system and capillary recruitment in humans is challenging, few studies have estimated insulin-induced changes in muscle microvasculature and evidence for the vascular action of insulin mainly has been deduced from its effect on total limb blood flow.

\section{Effect in Obese, Insulin-Resistant Individuals}

Impaired glucose uptake in skeletal muscle of obese, insulin-resistant individuals is tightly coupled with impaired insulin-induced effects on the microvasculature [13,194]. The microvasculature of 
skeletal muscle allows for early action of insulin to increase the surface area for glucose uptake and enhanced metabolism, even in the absence of increases in blood flow in the large conduit vessels. Therefore, diminished skeletal muscle microvascular recruitment may limit glucose disposal. The insulin-stimulated increases in skeletal muscle MBV and MBF observed in lean, healthy individuals did not occur in obese, insulin-resistant subjects with moderate hyperinsulinemia (1mU/kg/min) [47]. However, at higher doses $\left(120 \mathrm{mU} / \mathrm{m}^{2} / \mathrm{min}\right)$, insulin was capable of improving MBV and MFV significantly in obese, insulin-resistant individuals [143]. Similarly, Murdolo et al. [145] reported enhanced MBV and capillary recruitment in obese, insulin-resistant individuals after the application of high insulin doses $(100 \mathrm{mg} / \mathrm{min}$, equivalent to $\sim 22 \mathrm{mU} / \mathrm{kg} / \mathrm{min}$, assuming $1 \mathrm{mg}$ of insulin equals $24 \mathrm{mU}$ and that the average weight of the subjects was $109 \mathrm{~kg}$ ). These observations, taken together with the findings of Laakso et al. [111] concerning blood flow in conduit vessels, suggest that higher insulin doses are required for obese, insulin-resistant patients to achieve improved blood flow in either in their microvessels or their conduit vessels.

In conclusion, the evidence presented to this point has demonstrated that acute experimental hyperinsulinemia that mimics the physiological, postprandial rise in blood insulin levels causes enhancement of MBV and MBF in skeletal muscle tissue in healthy individuals (Table 3). However, insulin-stimulated blood flow in conduit vessels exhibited considerable divergence among the various studies that used low and moderate insulin doses (Table 1). Furthermore, studies that examined blood flow in conduit vessels and microvessels simultaneously, reported an earlier response to insulin and less dose-dependency in microvessels than conduit vessels $[50,65]$. In T2DM individuals, insulin-stimulated blood flow was blunted at all reported insulin doses $[82,111,156,158,189]$. However, in some of the obese, insulin-resistant 
cases, insulin-mediated increases in the blood flow in conduit vessels were achieved, albeit in response to higher doses and longer durations of exposure [110,120,143]. Similar findings were observed in MBV and MBF in response to moderate doses of insulin [47], which indicated an overall impairment in the vascular function throughout the arterial and arteriolar vascular tree in obese, insulin-resistant individuals.

\section{VASCULAR ACTION OF HYPERINSULINEMIA IN ANIMAL MODELS}

Data from animals generally demonstrate hyperinsulinemia-induced increases in total limb blood flow with parallel increases in capillary recruitment and microvascular perfusion [54,89,240,242]. However, insulin-stimulated total limb blood flow was blunted in insulin-resistant animals [46]. Likewise, in obese Zucker rats, microvascular recruitment in response to insulin was totally eliminated, and glucose disposal was dramatically impaired [251]. One study also indicated no association between insulin-induced total limb blood flow and microvascular reactivity, given microvascular recruitment was fully achieved in response to lower insulin concentrations (1 $\mathrm{mU} / \mathrm{kg} / \mathrm{min}$ ) [265]. Moreover, the maximum increase (plateau) in microvascular recruitment was reached at insulin infusion rates between 1 and $3 \mathrm{mU} / \mathrm{kg} / \mathrm{min}$, whereas total blood flow to the limbs continued to increase in response to higher insulin doses. Further, Zhang et al. [265] demonstrated microvascular changes at earlier time points than total limb blood flow response, which persisted for longer time after insulin cessation. These findings were verified by Vincent et al. [242], who reported insulin-augmented, microvascular perfusion within $30 \mathrm{~min}$, an effect that advanced the changes in femoral blood flow by 60-90 min. This dissociation between microvascular recruitment and total limb blood flow also was shown in response to other vasodilators. For instance, epinephrine infusions that enhanced total hind-limb blood flow in rats did not induce any changes in microvascular recruitment [42,173]. Similar findings were reported by Kuznetsova et al. [109] 
using angiotensin II or phenylephrine infusion into anesthetized rats during ganglionic blockade. From all of these observations, it can be concluded that microvascular recruitment and total limb blood flow may be regulated by two different, unrelated mechanisms. Also, microvessels may be more sensitive to insulin, resulting in a more rapid response and slower reversal to the basal state, than large conduit blood vessels.

\section{CELLULAR EVENTS RESPONSIBLE FOR INSULIN-MEDIATED VASCULAR}

\section{ACTION}

The discussion to this point has focused on the clinical vascular-related outcomes of acute experimental hyperinsulinemia. In this section, we investigate the clinical and experimental evidence regarding endothelial signaling under hyperinsulinemic versus physiological insulin levels. We also discuss the pathophysiological consequences of insulin resistance concerning the endothelial-mediated vascular function with a view toward its contribution to CVD. To date, three interactive mechanisms have been proposed for insulin's vascular actions. The first mechanism assumes that insulin's vascular effect is the result of the central stimulation of sympathetic nerve activity $[8,25,180,260]$. Despite the hypothetical sympathetic vasoconstrictor function of insulin, it is not clear under which conditions of insulin exposure (i.e. dose and duration) this effect prevails and surpasses insulin's anticipated vasodilatory effect. Studies that used adrenergic receptor blockers encountered minimal to no increases in insulin-stimulated blood flow, which might indicate that the sympathetic activity associated with the insulin is inhibiting excess vasodilation rather than inducing vasoconstriction [91,219].

The second mechanism that was proposed for insulin's vascular action is its direct effect on vascular smooth muscle tissue. It has been suggested that insulin induces the relaxation of vascular smooth muscle via regulating $\mathrm{Ca}^{2+}$ channel pump and membrane polarization [198]. 
Despite the strong experimental evidence regarding insulin's direct action on vascular smooth muscle cells $[115,230]$, it is uncertain whether insulin is capable of crossing the endothelial cell barrier to smooth muscle cells rapidly enough to induce its prompt vasodilatory effects [39,105].

Many investigators have suggested that the effect of insulin on vascular smooth muscle cells, even the transendothelial insulin transport, is mediated mainly by the endothelial cells $[108,172,239]$. This concept was supported by studies that showed that endothelial denudation disrupted vascular smooth muscle structure and insulin mediated vasomotor activity $[12,147,157]$. Thus, the third mechanism that has been proposed for insulin's vascular actions is mediated via an endothelium-dependent signaling pathway [171]. Due to the direct contact of endothelial cells with circulating blood, they are the first interface to interact with the insulin. They mediate insulin's vasomotor action mainly through releasing vasodilators and vasoconstrictors, such as NO and ET1, respectively, and maintaining these mediators in a balanced state [144]. Besides the simple diffusion of NO from endothelial cells to vascular smooth muscle cells, a new model for the regulation of NO access to smooth muscle cells by endothelial cells has been recently reported [213,214]. This model includes the formation of a macromolecular complex between hemoglobin $\alpha$ and eNOS at the myoendothelial junctions, which helps sequestering NO and reducing its bioavailability, probably as a mechanism of termination of its vasodilatory effects.

Insulin's vascular action is likely to be the outcome of an interaction among the three above-mentioned mechanisms. In this review, only the endothelium-dependent mechanism is discussed in the context of hyperinsulinemia and insulin resistance. For the sympathetic and the vascular smooth muscle mechanisms, the reader is directed to other reviews that provide comprehensive discussions of these pathways [191,198,215]. 


\section{Insulin Signaling in Vascular Endothelium - Vasodilation}

Several experimental studies using animal or in vitro models have provided mechanistic insight concerning insulin-stimulated endothelial functions, the most important of which is the release of endothelial NO [138,140,240,242,262,263]. These studies have described the insulin-signaling pathway starting from insulin binding to its receptor, and the activation of endothelial nitric oxide synthase (eNOS), the primary NO generator in endothelial tissue (Fig. 2). NO release is increased within minutes after endothelial exposure to insulin, and it has a crucial role in mediating insulinstimulated vascular action [190]. Insulin action on endothelial cells begins when insulin binds to its receptor, resulting in initiation of the receptor tyrosine kinase activity, followed by phosphorylation of the insulin receptor substrate-1 (IRS-1) [218]. The active (tyrosinephosphorylated) form of IRS-1 binds to and activates phosphatidylinositol 3-kinase (PI3K), and PI3K, in turn, activates a cascade of signaling proteins that includes phosphoinositide-dependent kinase-1 (PDK-1) and protein kinase B (AKT) [184]. Finally, this cascade leads to the activation of the enzyme, endothelial NO synthase (eNOS), through phosphorylation of the serine 1177 residue [103]. In the intact endothelial cells, the activated eNOS, in the presence of NADPH and the cofactors flavin adenine dinucleotide (FAD), flavin mononucleotide (FMN) and tetrahydrobipterin (BH4), catalyzes the oxidation of the amidine nitrogen in L-arginine producing the intermediate L-hydroxy arginine and subsequently NO and citrulline [5]. NO is a highly active gas that diffuses freely into the vascular smooth muscle tissue, where it acts to stimulate the guanylate cyclase enzyme, which converts guanosine triphosphate (GTP) into cyclic guanosine monophosphate (GMP) [188]. Cyclic GMP, in turn, activates protein kinase G, which causes concentration of $\mathrm{Ca}^{2+}$ to decrease through inhibiting $\mathrm{Ca}^{2+}$ mobilization from the sarcoplasmic reticulum [116] and increasing the conductance of $\mathrm{Ca}^{2+-}$ activated $\mathrm{K}^{+}$channels with subsequent 
hyperpolarization and reduction in $\mathrm{Ca}^{2+}$ influx through voltage-gated channels leading to relaxation of the vascular smooth muscle cells [146]. This signaling pathway, provoked by insulin, regulates capillary perfusion and thus contributes greatly to glucose metabolism in the skeletal muscle tissue. Furthermore, this pathway is critical in maintaining the balance between the vasodilatory and vasoconstrictive actions of insulin.

Scherrer et al. [190] demonstrated that insulin-induced blood flow in human skeletal muscle is dependent on NO and is abrogated by the NOS inhibitor, $\mathrm{N}^{\omega}$-nitro-L-arginine methyl ester (L-NAME). This study also demonstrated more reduction in forearm blood flow during a 2 hr hyperinsulinemic-euglycemic clamp than at baseline, indicating NO-dependence of insulin. These observations were supported by Steinberg et al., who reported $40 \%$ reduction in leg blood flow when L-NAME was infused with insulin versus $20 \%$ reduction when only saline was infused with L-NAME [208]. Baron et al. [16] showed that the increases in leg blood flow that were achieved in response to moderate $(1.1 \mathrm{mU} / \mathrm{kg} / \mathrm{min})$ and high $(3.2 \mathrm{mU} / \mathrm{kg} / \mathrm{min})$ doses of insulin were abrogated by L-NAME. The insulin dosage did not change the magnitude by which leg blood flow was reduced in response to L-NAME, however, the degree of insulin sensitivity did. The subjects who were more sensitive to insulin experienced greater L-NAME-induced reduction in leg blood flow, signifying the NO-dependence of insulin action. L-NAME has also been shown to diminish insulin-stimulated glucose uptake in human skeletal muscle $[14,16]$. Similar experiments with rats provided additional evidence that insulin-induced vasodilation in skeletal muscle is NOdependent. For instance, L-NAME infusion with insulin diminished insulin-induced microvascular recruitment and glucose uptake in rat skeletal muscle by $80 \%$ and $40 \%$, respectively [241]. Similarly, Roy et al. showed a marked suppression of insulin-stimulated glucose uptake and NOS activity upon constant infusion of L-NAME in rats [181]. In addition, endothelial denudation of 
isolated arterioles from rat cremaster muscle abolished insulin-stimulated arteriolar dilation [37]. Collectively, these studies provide solid evidence that endothelial-derived NO release is required for both the vascular and metabolic action of insulin in skeletal muscle. Nevertheless, alternative pathways may exist for insulin-mediated vasodilation. These include the activation of $\mathrm{Na}^{+}-\mathrm{K}^{+}$ adenosine triphosphatase (ATPase) located in endothelial or vascular smooth muscle cells leading to hyperpolarization and decreased $\mathrm{Ca}^{2+}$ influx and subsequent vasodilation [220]. Furthermore, involvement of the metabolic vasodilator, adenosine, in insulin-mediated vasodilation has been suggested $[2,27,177]$. Intra-brachial infusion of draflazine (an adenosine-uptake blocker) during a hyperinsulinemic-euglycemic clamp enhanced the insulin-stimulated forearm blood flow however, infusion of theophylline (an adenosine-receptor antagonist) inhibited forearm blood flow in healthy individuals [2]. One can speculate that insulin-induced vasodilation is the outcome of an interaction among all the above-mentioned mechanisms.

\section{Insulin Signaling in Vascular Endothelium - Vasoconstriction}

While the role of insulin in stimulating endothelial NO release and inducing vasodilation is well established, only recently have investigators recognized insulin signaling pathways that induce the release of endothelial-derived ET-1 [68]. Activation of the insulin receptor by insulin leads to activation of the guanine nucleotide exchange factor Son of Sevenless (SOS) which subsequently promotes the switch of the guanosine diphosphate (GDP) in rat sarcoma (RAS) to a guanosine triphosphate (GTP) resulting in activation of RAS [164]. The activated RAS then initiates a kinase phosphorylation cascade involving rapidly accelerated fibrosarcoma (RAF), and mitogenactivated protein kinase (MAPK) signaling pathway. MAPK signaling involves a cascade of intermediate signaling kinases, such as MAPK kinase (MEK), extracellular signal-regulated kinases 1 and 2 (ERK1/2) that regulates biological actions related to growth, proliferation, and 
differentiation and is also involved in insulin-induced secretion of pro-ET-1 [165] (Fig. 2). ProET-1 is a big non-functioning protein that needs to be cleaved to the smaller active form, ET-1, via the endothelin-converting enzyme (ECE). ET-1 is the most potent and predominant endothelial-derived vasoconstrictor in the human cardiovascular system [136]. ET-1 acts mainly through binding to endothelin type $\mathrm{A}\left(\mathrm{ET}_{\mathrm{A}}\right)$ and endothelin type $\mathrm{B}\left(\mathrm{ET}_{\mathrm{B}}\right)$ receptors (Fig. 3). $\mathrm{ET}_{\mathrm{A}}$ receptors are located on the surface of vascular smooth muscle cells [67]. The binding of ET-1 to $\mathrm{ET}_{\mathrm{A}}$ receptors activates a heterotrimeric GDP-binding protein that consists of $\alpha, \beta$ and $\gamma$ subunits. The exchange of GDP for GTP activates the heterotrimeric protein leading to the dissociation of $\alpha$ subunit from the complex and initiation of downstream signaling pathways that includes activation of phospholipase C/inositol triphosphate (PLC/IP3) [163]. IP3 diffuses into the cytoplasm and increases $\mathrm{Ca}^{2+}$ release from intracellular calcium stores leading to the contraction of vascular smooth muscle cells and vasoconstriction [77]. In addition, ET-1 binding to $\mathrm{ET}_{\mathrm{A}}$ receptors activates protein kinase $\mathrm{C}$ (PKC) which is also involved in mediating ET-1-induced signaling events in vascular smooth muscle cells such as proliferation and contraction [133]. $\mathrm{ET}_{\mathrm{B}}$ receptors are highly expressed on endothelial cells, yet are also found in a lower density on vascular smooth muscle cells. $\mathrm{ET}_{\mathrm{B}}$ receptors have different isoforms and functions depending on the cell type, vasodilators in endothelial cells $\left(\mathrm{ET}_{\mathrm{B} 1}\right)$ and vasoconstrictors in vascular smooth muscle cells $\left(\mathrm{ET}_{\mathrm{B} 2}\right)$. Binding of $\mathrm{ET}-1$ to $\mathrm{ET}_{\mathrm{B} 1}$ receptors located on the surface of endothelial cells, activates eNOS signaling via the PI3/AKT pathway and subsequently induces NO production and vasodilation $[32,123]$. Alternative mechanisms for $\mathrm{ET}_{\mathrm{B} 1}$ receptor-mediated vasodilation have been also suggested such as inducing the relaxing factors, prostacyclin and endothelium-derived hyperpolarizing factor and mediating ET-1 internalization, metabolism and clearance [97]. On the contrary, binding of ET-1 to $\mathrm{ET}_{\mathrm{B} 2}$ receptors on vascular smooth muscle cells induces the same 
signaling pathways described for $\mathrm{ET}_{\mathrm{A}}$ receptors (i.e. PLC/IP3), resulting in induction of intracellular $\mathrm{Ca}^{2+}$ and subsequently, smooth muscle cell contraction [132].

Thus, ET-1 seems to be a vasoactive mediator with a dual function [101]. In humans, the concentration of ET-1 in skeletal muscle tissue is 100 -fold higher than its circulating levels, implying a paracrine role of ET-1 in regulating vascular tone [101]. Interestingly, data from human studies [85] and animal studies [34,118] demonstrate increases in circulating ET-1 after blockade of $\mathrm{ET}_{\mathrm{A}}$ and $\mathrm{ET}_{\mathrm{B}}$ receptors. This observation is thought to be the result of the antagonist displacing ET-1 from its binding sites in tissue receptors.

Haynes et al. showed that local intra-arterial infusion of proendothelin-1 or ET-1 caused vasoconstriction of the brachial artery and reduction in forearm blood flow. This effect was abolished by concomitant infusion with phosphoramidon, an ECE inhibitor, or with BQ-123, an $\mathrm{ET}_{\mathrm{A}}$ antagonist [86]. In the same study, vasodilation of the brachial artery and increased forearm blood flow were achieved in response to infusion with BQ-123 alone. These observations are supported by data from other studies demonstrating increases in arterial vasodilation, enhancement of limb blood flow, and decreased vascular resistance in healthy individuals after local infusion of $\mathrm{ET}_{\mathrm{A}}$ antagonist alone or in combination with an $\mathrm{ET}_{\mathrm{B}}$ antagonist $[26,85,238]$. Data from a study by Shemyakin et al. [197] demonstrated that dual blocking of $\mathrm{ET}_{\mathrm{A}}$ and $\mathrm{ET}_{\mathrm{B}}$ during the hyperinsulinemic-euglycemic clamp caused greater enhancement of skeletal muscle blood flow and glucose uptake in lean, healthy individuals than insulin infusion alone. Several studies have shown that ECE inhibitors and ET-1 receptor antagonists reduce systemic blood pressure comparably in hypertensive and normotensive states $[49,73,237]$. However, other studies have reported reduction in blood pressure in response to ET-1 blocking only in hypertensive adults and animal models, whereas no effect was seen with normotensive conditions $[22,153,250,254]$. 
Accordingly, some investigators have suggested that ET-1 has a pathological role rather than a physiological role.

The fact that the ET-1 receptor blockade potentiates the vasodilatory effects of insulin provides compelling evidence that insulin maintains a balance between two opposing hemodynamic pathways [262]. In support of this conclusion, Ross et al. [179] showed that, while ET-1 infusion alone did not induce significant changes in skeletal muscle hemodynamics or glucose metabolism, a concomitant infusion of ET-1 with insulin $(10 \mathrm{mU} / \mathrm{kg} / \mathrm{min})$ reduced blood flow and glucose uptake. Nevertheless, some investigators reported augmentation of insulinstimulated skeletal muscle blood flow and glucose uptake in response to ET-1 receptor antagonism only in obese, insulin-resistant subjects $[120,196]$. Despite the experimental evidence for insulinmediated regulation of endothelial ET-1 production, clinical findings are contradictory. It is not clear to what extent insulin-stimulated ET-1 production contributes to maintaining vascular homeostasis in physiological settings, and further investigations are warranted to elucidate this mechanism.

\section{Hyperinsulinemia and Vascular Homeostasis}

At physiological levels, insulin appears to regulate vascular homeostasis by maintaining the balance of endothelial-derived NO and ET-1 via regulating two critical signaling pathways, PI3K and MAPK [144]. Treatment of endothelial cells with wortmannin, a PI3K inhibitor, results in suppression of eNOS expression and the subsequent NO production. However, additional activation of MAPK and an increase in ET-1 expression were observed when wortmannin and insulin were applied simultaneously $[139,164]$. Thus, it was suggested that the loss of balance between these two pathways is a primary feature in the pathogenesis of hyperinsulinemia-induced vascular dysfunction [164]. This imbalance has been attributed to the selective nature of insulin 
resistance that typically is characterized by the attenuation of the PI3K-eNOS pathway, while the integrity of the MAPK-ET-1 pathway is maintained, favoring the vasoconstrictor action of insulin [164] (Fig. 4). However, it is not clear whether hyperinsulinemia alone, in isolation from insulin resistance, is capable of disturbing the vasomotor balance. As was demonstrated earlier regarding healthy individuals (Table 1), the effect of hyperinsulinemia on vascular tone and homeostasis was contradictory among studies that, for the most part, failed to provide a mechanistic explanation for these discrepant findings.

Circulating levels of ET-1 are higher in obese and T2DM subjects versus healthy controls, and the levels are proportional to the degree of hyperinsulinemia $[70,71,93,103,222]$. It is worth mentioning that ET-1 per se plays a critical role in the development of insulin resistance and endothelial dysfunction in skeletal muscle [195]. In support of this hypothesis, molecular studies using chronic ET-1 treatment resulted in suppression of the PI3K/AKT signaling pathway by inhibiting the phosphorylation of insulin receptor substrates IRS-1 and IRS-2 [94], or by interfering with phosphatidylinositol 4,5-bisphosphate PIP2 function as an intermediate in the IP3 pathway [216]. In obese subjects and in subjects with T2DM, insulin infusion for 2 hrs (287 $\mathrm{pmol} / \mathrm{m}^{2} / \mathrm{min}$, or $\sim 1.1 \mathrm{mU} / \mathrm{kg} / \mathrm{min}$ ) caused marked elevation of plasma levels of ET-1 [72]. Several in vitro studies, such as the human umbilical vein endothelial cell (HUVEC) model, have also reported increased ET-1 expression in response to insulin treatment [38,72,248]. Thus, it seems reasonable to assume that antagonizing ET-1 signaling may provide an ideal therapeutic target in an insulin-resistant population. ET-1 receptor antagonism in obese and T2DM subjects generated more consistent data than studies in lean, healthy individuals, indicating that the activity of endogenous ET-1 may be enhanced in subjects with insulin resistance. For instance, Lteif et al. [120] demonstrated blockade of $\mathrm{ET}_{\mathrm{A}}$ in the femoral artery during insulin infusion resulted in 
augmented leg blood flow and skeletal muscle glucose uptake in obese subjects. In addition, it has been reported that ET-1 antagonism increases NO synthesis, restores NO bioavailability, and reduces blood pressure in obese and diabetic individuals [130,131]. Collectively, these data support the contention that hyperinsulinemia-induced ET-1 contributes to insulin resistanceassociated vascular dysfunction, thus leading to a progressive, deleterious spiral of events. Such complications include diminished delivery of insulin and nutrients to skeletal muscle and, subsequently, the reduced uptake and metabolism of glucose.

While the above-mentioned studies established a role for hyperinsulinemia in augmenting ET-1 production and its vasoconstrictor effect, another important question remains to be answered is whether hyperinsulinemia stimulates NO release in a way that maintains the balance with ET-1. The current evidence for the involvement of NO-dependence during hyperinsulinemia was deduced mostly from studies that measured NO indirectly. Nevertheless, fewer studies have measured the change in NO concentrations in response to acute hyperinsulinemia [202,232,261]. Moreover, because of the very short half-life of NO (3-4 seconds), these studies used methods based on measuring NO metabolites (nitrates and nitrites) to estimate NO concentrations. Although these methods do not completely reflect the biological activity of NO, they currently provide a standard tool for estimating NO concentrations. Using this approach, Tsukahara et al. [231] demonstrated that urinary levels of nitrates and nitrites increased significantly in lean, healthy subjects after a single, intravenous injection of insulin $(0.1 \mathrm{mU} / \mathrm{kg})$. Solomon et al. [202] showed progressive decline in plasma NO bioavailability across the glucose tolerance continuum in older, obese subjects. However, they reported no significant changes in plasma NO in response to acute hyperinsulinemia ( $40 \mathrm{mU} / \mathrm{m}^{2} / \mathrm{min}$, equivalent to $\left.1.1 \mathrm{mU} / \mathrm{kg} / \mathrm{min}\right)$. Similarly, Eid et al. [66] reported a null effect of insulin administration on plasma NO levels in subjects with borderline 
hypertension. Tessari et al. [227,228] used a unique approach employing infusion of stable isotope labeled L-arginine to examine the conversion of L-arginine to NO. Using this method, they showed that insulin's ability to induce NO synthesis was several-fold lower in subjects with T2DM than in lean, heathy controls.

All the above-mentioned studies used various methods to estimate the NO concentration in blood. However, because no half-life and metabolism of NO by the erythrocytes is rapid, most methods underestimate the biological activity of NO. Only scattered studies have investigated the effect of hyperinsulinemia on local NO metabolism in skeletal muscle. In a study by Kashyap et al. [100], a four-hour hyperinsulinemic-euglycemic clamp $\left(80 \mathrm{mU} / \mathrm{m}^{2} / \mathrm{min}\right.$, equivalent to $\sim 2.2$ $\mathrm{mU} / \mathrm{kg} / \mathrm{min}$ ) induced a two-fold increase in the NOS activity in skeletal muscle of lean, healthy individuals. However, the same research group reported no changes in NOS activity in subjects with T2DM [99]. Collectively, these studies provide some evidence for the impaired sensitivity of the NO pathway to acute, short-term hyperinsulinemia in insulin-resistant subjects, which results in the unopposed vasoconstrictor activity of ET-1. Nevertheless, there are no data available regarding the effect of prolonged hyperinsulinemia on either insulin-resistant or healthy individuals. Madonna et al. [126] reported detrimental effects of prolonged hyperinsulinemia in cultured human endothelial cells. In this study, although short-term (30 min) hyperinsulinemia enhanced the phosphorylation of NOS and NO production, long-term insulin treatment (three days) suppressed the PI3K/eNOS axis and inhibited NO production. In addition, chronic administration of insulin (days to weeks) decreased the number of insulin receptors and reduced insulin sensitivity in rats $[106,128]$. On the basis of such observations, investigating the potential detrimental effects of prolonged hyperinsulinemia in humans, although challenging, is warranted. 
Hyperinsulinemia-induced vascular dysfunction has traditionally thought to be mediated mainly through the disturbed balance between vasodilators and vasoconstrictors [104]. Another mechanism that could explain the vascular dysfunction associated with hyperinsulinemia deals with the generation of reactive oxygen species (ROS). In vascular smooth muscle cells, insulin treatment induced oxidative stress via increased nicotinamide adenine dinucleotide phosphate (NADPH) oxidase activity and subsequent superoxide generation [4]. Similar findings have been reported in aortic endothelial cells in which superoxide generation increased two-fold following both acute and chronic exposure to insulin [98]. Hyperinsulinemia was also shown to inhibit catalase activity and increase hydrogen peroxide $\left(\mathrm{H}_{2} \mathrm{O}_{2}\right)$ production in rats [255]. This increase in $\mathrm{H}_{2} \mathrm{O}_{2}$ displayed a significant negative linear correlation with serum insulin levels. Another potential mechanism by which insulin may increase ROS formation is through NO production. Even though this mechanism is impaired in the case of insulin resistance, residual amounts of NO interact with superoxide radicals, leading to the formation of peroxynitrite, which is capable of uncoupling eNOS and inhibiting antioxidant enzymes, such as manganese superoxide dismutase (MnSOD) [125]. Recently, Sanchez et al. [185] reported that ET-1 infusion in rats stimulated superoxide generation by activating the $\mathrm{ET}_{\mathrm{A}}$-mediated $\mathrm{NADPH}$ oxidase system, which further contributed to ET-1-induced impairment of the NO pathway. From what was mentioned above, it is conceivable that hyperinsulinemia-induced ET-1 over-expression and increased oxidative stress are two intertwined mechanisms that act in concert to potentiate endothelial dysfunction in insulin resistance.

\section{THE LINK BETWEEN HYPERINSULINEMIA AND CVD}

The risk of CVD and stroke is three to four-fold greater in individuals with obesity and diabetes than in the general, age-matched population [95,114]. The association between these metabolic 
disorders and the development of CVD is believed to be multifactorial, with insulin resistance and the accompanying compensatory hyperinsulinemia, acting as major contributors $[56,161]$. Insulin resistance is strongly association with the risk of CVD independent of other risk factors, such as reduced physical activity, obesity, glucose intolerance, and dyslipidemia [30,31,84]. Similarly, in two longitudinal studies, insulin resistance was highly predictive of subsequent coronary heart disease, stroke, and transient ischemic attacks in elderly men [252,264]. In addition, insulin resistance is highly prevalent in non-diabetic patients with coronary heart disease and is linked to decreased exercise capacity and increased CVD risk factors, such as waist circumference, high levels of leptin, and endothelial dysfunction [6]. Several mechanisms have been suggested to explain the biological link between insulin resistance and CVD. The primary mechanisms is believed to be hyperinsulinemia-induced endothelial dysfunction, which is also considered to be a key feature in insulin resistance [120]. Vascular endothelium is the first responder to insulin's action and is considered as a prime target for insulin resistance [102]. The facts that endothelial cells are the first to encounter blood-born nutrients and insulin resistance is rapidly developed in response to high fat diet [211] suggest that the response of endothelial cells precedes that of other insulin-targeted tissues. Insulin-resistant endothelial cells greatly contribute to the manifestations and consequences of insulin resistance elsewhere in the body and is considered as a link between vascular and metabolic insulin resistance [21]. Moreover, endothelial dysfunction independently predicts cardiac mortality, myocardial infarction, and stroke [29] and is considered to be an early event in the development of cardiometabolic syndrome development [166]. Hyperinsulinemiainduced endothelial dysfunction in skeletal muscle is characterized by the following interrelated vascular pathologies that contribute to the risk of developing CVD. 


\section{Vasomotor Imbalance}

Dysfunctional endothelial cells release lower levels of NO and higher levels of ET-1, which favors vasoconstriction and poor capillary perfusion. This impairs insulin delivery to skeletal muscle [17], reduces the transport and disposal of nutrients [181], and results in disturbances in carbohydrate and lipid metabolism [243]. As a consequence, a cluster of metabolic abnormalities occur, such as hyperglycemia, hypertriglyceridemia, and hypercholesterolemia [3]. These metabolic derangements enhance inflammation and oxidative stress and cause further damage to the vascular endothelium, which support the hypothesis that endothelial dysfunction could be a cause and a consequence of metabolic disturbances. Thus, the lack of NO bioavailability generates a vicious cycle, which further contributes to the pathogenesis of insulin resistance-induced vascular dysfunction. Hyperinsulinemia is also known to stimulate pro-atherogenic [11,51], pro-coagulant [137], pro-adhesive, pro-inflammatory [74,137,205,253], and oxidative stress-inducing [249] pathways, as well as inducing smooth muscle cell proliferation and hypertrophy [52]. This sequelae contributes to the development of hypertension, atherosclerosis, and many other manifestations of CVD. Figure 5 summarizes the hypothesized pathways and molecules involved in hyperinsulinemia-induced ET-1 production which exacerbate vascular dysfunction.

In addition, while skeletal muscle rely on insulin-regulated pathways for their supply of glucose, endothelial cells are able to take up glucose independently from the action of insulin. This assumption is built on the observation that skeletal muscle cells express insulin-dependent glucose transferase-4 (GLUT-4) while endothelial cells have insulin-independent glucose transporters, glucose transferase-1 (GLUT-1), as well [63]. This diverse distribution of glucose transferases creates an imbalance in which the hyperinsulinemic-hyperglycemic state that develops due to insulin resistance leads to an unregulated rush of glucose into the endothelial cells with collateral 
glucose starvation at the level of skeletal muscle [19]. As a consequence, a vicious cycle of proinflammatory signaling and oxidative stress is generated leading to worsening of the insulinresistance state and its related cardiovascular risk.

\section{Inflammation and Oxidative Stress}

In response to inflammation and oxidative stress, activated endothelial cells express cell surface adhesion molecules, such as intracellular adhesion molecule-1 (ICAM-1), vascular cell adhesion molecule-1 (VCAM-1), E-selectin, and P-selectin. These molecules result in the recruitment of inflammatory cells to the wall of blood vessels and in augmented production of inflammatory cytokines, such as interleukin (IL)-1, IL-6, IL-8, tumor necrosis factor alpha (TNF- $\alpha$ ), interferon gamma (IFN- $\gamma$ ), and C-reactive protein (CRP) [160]. In addition, adhesion molecules on the surfaces of endothelial cells facilitate platelet aggregation and adhesion. In the absence of an opposing vasodilatory action mediated via endothelial NO, this inflammatory milieu predisposes patients to coagulation disorders and atherosclerosis [124]. Inflammation and oxidative stress are closely related, since they share most of the signaling pathways, and the presence of one always triggers the occurrence of the other. Oxidative stress has been implicated in almost all the key steps in the pathogenesis of CVD, such as endothelial dysfunction, eNOS uncoupling, NO degradation, dyslipidemia and lipid oxidation, vascular remodeling, atheroma formation and atherosclerosis, and acute thrombotic events [159]. ROS also result in suppression of the activity of antioxidant enzymes, such as glutathione peroxidase and superoxide dismutase [75]. The role of oxidative stress and ROS in inducing endothelial dysfunction in skeletal muscle of metabolicallycompromised humans was discussed comprehensively in a review by Goodwill and Frisbee [80]. 


\section{Advanced Glycation End-products (AGEs)}

Recently, AGEs and their receptor, known as receptor of AGEs (RAGE), have been implicated in the pathogenesis of CVD in patients with T2DM [78]. AGEs are formed via non-enzymatic protein glycation, and they contribute significantly to inflammation and oxidative stress [41,212]. AGEs are of clinical importance because there is increasing evidence that they have a pivotal role in the biology of the development of insulin resistance-related CVD [96,134]. They may exert their detrimental cellular effects directly, or via binding to RAGE that is expressed on the surfaces of several types of cells. AGEs cause vascular abnormalities that are irreversible even after maintaining a good control of blood glucose. These abnormalities have been referred to as the "metabolic memory" which indicates long-term effects of earlier metabolic derangements that accelerated the formation and accumulation of AGEs [257,258]. Several mechanisms for the contribution of AGEs to endothelial dysfunction have been proposed. For instance, AGEs formed in the extracellular matrix reduces the elasticity and induces stiffness of the vascular wall predisposing to atherosclerotic diseases [259]. Also, they scavenge NO and reduces its bioavailability resulting in impaired endothelium-dependent vasodilatation [193]. Moreover, there is a growing body of evidence that binding of AGEs to RAGE induces oxidative stress and proinflammatory signaling pathways such as nuclear factor kappa-light-chain-enhancer of activated B cells $(\mathrm{NF \kappa B})$, that further contribute to the development and progression of CVD [256].

\section{Matrix Remodeling and Arterial Stiffness}

Matrix remodeling and arterial stiffness are established predictors of cardiovascular risk that could propose a possible link between hyperinsulinemia-induced endothelial dysfunction and CVD pathogenesis $[7,162]$. Beyond the functional changes, insulin resistance and the associated hyperinsulinemia induce structural changes in the vascular wall. Many mechanisms have been 
proposed for insulin resistance-induced vascular stiffness, including: 1) the activation of insulin growth factor-1 (IGF-1) by compensatory hyperinsulinemia, which induces the proliferation and migration of smooth muscle cells to the intima and secretion of collagen that leads to the formation of fibrous plaques and atherosclerotic lesions [182];2) lipid deposition and oxidative stress to the vessel wall, which triggers an inflammatory reaction with subsequent destruction of elastin and accumulation of extracellular matrix proteins, such as collagen; this results in reduced vascular wall compliance and elasticity [206]; 3) increased expression and activity of angiotensin 1 receptor in the vasculature which results in decreased vascular compliance [33]; and 4) reduced vascular tone caused by impaired NO production. All of these factors contribute to the reduction of vascular compliance and the induction of arterial stiffness associated with insulin resistance, both of which are key factors in the development of atherosclerosis and hypertension [40,122,127].

\section{Endothelial Barrier: Glycocalyx and Transcytosis}

It is currently well established that insulin's delivery to skeletal muscle is controlled by capillary perfusion. However, another candidate mechanism that could control the delivery of insulin to muscle is the active movement of insulin across the endothelial cell barrier $[23,83,207]$. There is a growing body of evidence that insulin's accessibility to tissue and its ability to improve blood flow and capillary recruitment depend to a certain extent, on a reciprocal relationship between insulin and the endothelial glycocalyx [69]. The glycocalyx is a gel-like layer that consists of a network of proteoglycans, glycoproteins, and glycosaminoglycans that acts as a barrier between circulating blood and the endothelium [152]. In normal physiological states, insulin modifies the structure and function of the glycocalyx, promoting the delivery of more insulin and blood to the target tissue [69]. However, in insulin resistance, the glycocalyx becomes less accessible to blood and large molecules, such as insulin. These structural changes and abnormalities in the glycocalyx 
have been well-correlated with capillary recruitment across the glucose-tolerance continuum [81]. In addition to its interactive role with insulin to control the accessibility of blood for tissues, the glycocalyx also acts as a mechanosensor and a transducer that transmits the shear stress to the endothelial cells, resulting in increased production of NO [223]. Thus, it is likely that the attenuation of the glycocalyx can explain, in part, the disturbance in NO release and the impaired vasodilation in insulin-resistant individuals.

Insulin transcytosis is another way for insulin to traverse the endothelial barrier. Recently, it was shown that insulin resistance-induced endothelial dysfunction is associated with impaired insulin transcytosis across endothelial cells [247]. Moreover, the myoendothelial junction, which has been cited as a possible key element in NO signaling and diffusion in endothelial cells [214], is affected adversely both quantitatively and morphologically by endothelial dysfunction [87]. Collectively, derangements in the glycocalyx or the transcytosis process result in impairment of insulin delivery to muscle tissues, resulting in several vascular and metabolic complications.

Overall, all the above-mentioned pathophysiological mechanisms that link insulin resistance and the associated hyperinsulinemia to vascular dysfunction, act in a reciprocal, intertwined fashion. It is sometimes difficult to determine if these phenotypes are a cause or a consequence of vascular dysfunction. Nevertheless, recent evidence suggests that some of these pathological abnormalities exist as early events in insulin resistance [45] which supports the contributing role of the latter to vascular dysfunction and subsequently the development of CVD.

\section{CONCLUSION}

The vascular action of insulin has been increasingly recognized in the past two decades. Accordingly, the link between insulin resistance and CVD is becoming increasingly clear and the contribution of low insulin delivery to the impaired insulin-mediated glucose disposal, in insulin 
resistant skeletal muscle, is becoming more apparent. Hyperinsulinemia is an integral component of insulin resistance and both are biologically intertwined, however, within this context it is hard to conclude whether hyperinsulinemia is the cart or the horse. There is growing evidence for the contribution of chronic hyperinsulinemia to vascular dysfunction and CVD. Nevertheless, the discrepancy in studies that examined the effect of hyperinsulinemia on vascular function requires that further work be done. Hyperinsulinemia did not induce the same effect among different studies and among different subjects within each study. This may indicate the presence of interactions between hyperinsulinemia and other risk factors such as glucose levels, lipid profile, blood pressure, etc. It is also important to know that hyperinsulinemia can be a consequence of insulin treatment in insulin-dependent and some insulin-independent diabetic patients. This emphasizes the need to investigate the potential detrimental effects of hyperinsulinemia on the vascular and metabolic function. In this review, we explicitly addressed, at both the clinical and the molecular level, vascular action of insulin and vascular dysfunction associated with hyperinsulinemia as well as the underlying mechanisms that link hyperinsulinemia to the high risk of developing CVD.

\section{PERSPECTIVES}

Compensatory hyperinsulinemia associated with insulin resistance is considered to be one of the major mechanisms that promote vascular dysfunction in metabolically compromised patients. Nevertheless, more work needs to be done to fill the gap between experimental models of hyperinsulinemia and chronic compensatory hyperinsulinemia associated with insulin resistance. There is a need for more controlled studies into the vascular effects of insulin where the metabolic profile of subjects and other factors that may influence the outcome such as diet and different diabetes treatment modalities are more adjusted. Also there is an imminent need for more sensitive tools to measure skeletal muscle microvascular density in vivo since the available tools such as 
capillary video-microscopy and laser Doppler ultrasound are restricted to skin perfusion with limited penetration depth. Finally, insulin resistance and the associated hyperinsulinemia are multifaceted conditions that threatens the health of millions of people. Understanding the mechanisms by which insulin resistance induces vascular dysfunction is critically important for the prevention and/or treatment of cardiometabolic disorders. 


\section{REFERENCES}

1. Abbatecola AM, Paolisso G, Fattoretti P, Evans WJ, Fiore V, Dicioccio L, Lattanzio F. Discovering pathways of sarcopenia in older adults: a role for insulin resistance on mitochondria dysfunction. The journal of nutrition, health \& aging 15: 890-895, 2011.

2. Abbink-Zandbergen EJ, Vervoort G, Tack CJ, Lutterman JA, Schaper NC, Smits P. The role of adenosine in insulin-induced vasodilation. Journal of cardiovascular pharmacology 34: 374-380, 1999.

3. Abdul-Ghani MA, DeFronzo RA. Pathogenesis of insulin resistance in skeletal muscle. Journal of biomedicine \& biotechnology 2010: 476279, 2010.

4. Abhijit S, Bhaskaran R, Narayanasamy A, Chakroborty A, Manickam N, Dixit M, Mohan V, Balasubramanyam M. Hyperinsulinemia-induced vascular smooth muscle cell (VSMC) migration and proliferation is mediated by converging mechanisms of mitochondrial dysfunction and oxidative stress. Molecular and cellular biochemistry 373: 95-105, 2013.

5. Alderton WK, Cooper CE, Knowles RG. Nitric oxide synthases: structure, function and inhibition. The Biochemical journal 357: 593-615, 2001.

6. AlZadjali MA, Godfrey V, Khan F, Choy A, Doney AS, Wong AK, Petrie JR, Struthers AD, Lang CC. Insulin resistance is highly prevalent and is associated with reduced exercise tolerance 
in nondiabetic patients with heart failure. Journal of the American College of Cardiology 53: 747$753,2009$.

7. Amar J, Ruidavets JB, Chamontin B, Drouet L, Ferrieres J. Arterial stiffness and cardiovascular risk factors in a population-based study. Journal of hypertension 19: 381-387, 2001.

8. Anderson EA, Hoffman RP, Balon TW, Sinkey CA, Mark AL. Hyperinsulinemia produces both sympathetic neural activation and vasodilation in normal humans. The Journal of clinical investigation 87: 2246-2252, 1991.

9. Aoki K, Kato H, Terauchi Y. Divided-dose administration of miglitol just before and 15 minutes after the start of a meal smoothes postprandial plasma glucose excursions and serum insulin responses in healthy men. Endocrine journal 54: 1009-1014, 2007.

10. Arcaro G, Cretti A, Balzano S, Lechi A, Muggeo M, Bonora E, Bonadonna RC. Insulin causes endothelial dysfunction in humans: sites and mechanisms. Circulation 105: 576-582, 2002.

11. Babaei S, Picard P, Ravandi A, Monge JC, Lee TC, Cernacek P, Stewart DJ. Blockade of endothelin receptors markedly reduces atherosclerosis in LDL receptor deficient mice: role of endothelin in macrophage foam cell formation. Cardiovascular research 48: 158-167, 2000. 
12. Bailey SR, Mitra S, Flavahan S, Bergdall VK, Flavahan NA. In vivo endothelial denudation disrupts smooth muscle caveolae and differentially impairs agonist-induced constriction in small arteries. Journal of cardiovascular pharmacology 49: 183-190, 2007.

13. Baron AD. Hemodynamic actions of insulin. The American journal of physiology 267: E187202, 1994.

14. Baron AD, Brechtel-Hook G, Johnson A, Cronin J, Leaming R, Steinberg HO. Effect of perfusion rate on the time course of insulin-mediated skeletal muscle glucose uptake. The American journal of physiology 271: E1067-1072, 1996.

15. Baron AD, Brechtel-Hook G, Johnson A, Hardin D. Skeletal muscle blood flow. A possible link between insulin resistance and blood pressure. Hypertension 21: 129-135, 1993.

16. Baron AD, Steinberg HO, Chaker H, Leaming R, Johnson A, Brechtel G. Insulin-mediated skeletal muscle vasodilation contributes to both insulin sensitivity and responsiveness in lean humans. The Journal of clinical investigation 96: 786-792, 1995.

17. Baron AD, Tarshoby M, Hook G, Lazaridis EN, Cronin J, Johnson A, Steinberg HO. Interaction between insulin sensitivity and muscle perfusion on glucose uptake in human skeletal muscle: evidence for capillary recruitment. Diabetes 49: 768-774, 2000. 
18. Barrett EJ, Eggleston EM, Inyard AC, Wang H, Li G, Chai W, Liu Z. The vascular actions of insulin control its delivery to muscle and regulate the rate-limiting step in skeletal muscle insulin action. Diabetologia 52: 752-764, 2009.

19. Barrett EJ, Liu Z. The endothelial cell: an "early responder" in the development of insulin resistance. Reviews in endocrine \& metabolic disorders 14: 21-27, 2013.

20. Barrett EJ, Rattigan S. Muscle perfusion: its measurement and role in metabolic regulation. Diabetes 61: 2661-2668, 2012.

21. Barrett EJ, Wang H, Upchurch CT, Liu Z. Insulin regulates its own delivery to skeletal muscle by feed-forward actions on the vasculature. American journal of physiology. Endocrinology and metabolism 301: E252-263, 2011.

22. Bazil MK, Lappe RW, Webb RL. Pharmacologic characterization of an endothelinA (ETA) receptor antagonist in conscious rats. Journal of cardiovascular pharmacology 20: 940-948, 1992.

23. Bendayan M, Rasio EA. Transport of insulin and albumin by the microvascular endothelium of the rete mirabile. Journal of cell science 109 ( $\mathbf{P t}$ 7): 1857-1864, 1996.

24. Bergman RN, Finegood DT, Ader M. Assessment of insulin sensitivity in vivo. Endocrine reviews 6: 45-86, 1985. 
25. Berne C, Fagius J, Pollare T, Hjemdahl P. The sympathetic response to euglycaemic hyperinsulinaemia. Evidence from microelectrode nerve recordings in healthy subjects. Diabetologia 35: 873-879, 1992.

26. Berrazueta JR, Bhagat K, Vallance P, MacAllister RJ. Dose- and time-dependency of the dilator effects of the endothelin antagonist, BQ-123, in the human forearm. British journal of clinical pharmacology 44: 569-571, 1997.

27. Bijlstra P, van Ginneken EE, Huls M, van Dijk R, Smits P, Rongen GA. Glyburide inhibits dipyridamole-induced forearm vasodilation but not adenosine-induced forearm vasodilation. Clinical pharmacology and therapeutics 75: 147-156, 2004.

28. Bonadonna RC, Saccomani MP, Del Prato S, Bonora E, DeFronzo RA, Cobelli C. Role of tissue-specific blood flow and tissue recruitment in insulin-mediated glucose uptake of human skeletal muscle. Circulation 98: 234-241, 1998.

29. Bonetti PO, Lerman LO, Lerman A. Endothelial dysfunction: a marker of atherosclerotic risk. Arteriosclerosis, thrombosis, and vascular biology 23: 168-175, 2003.

30. Bonora E, Formentini G, Calcaterra F, Lombardi S, Marini F, Zenari L, Saggiani F, Poli M, Perbellini S, Raffaelli A, Cacciatori V, Santi L, Targher G, Bonadonna R, Muggeo M. HOMA- 
estimated insulin resistance is an independent predictor of cardiovascular disease in type 2 diabetic subjects: prospective data from the Verona Diabetes Complications Study. Diabetes care 25: 1135$1141,2002$.

31. Bonora E, Kiechl S, Willeit J, Oberhollenzer F, Egger G, Meigs JB, Bonadonna RC, Muggeo M. Insulin resistance as estimated by homeostasis model assessment predicts incident symptomatic cardiovascular disease in caucasian subjects from the general population: the Bruneck study. Diabetes care 30: 318-324, 2007.

32. Bouallegue A, Daou GB, Srivastava AK. Endothelin-1-induced signaling pathways in vascular smooth muscle cells. Current vascular pharmacology 5: 45-52, 2007.

33. Brillante DG, O'Sullivan AJ, Howes LG. Arterial stiffness in insulin resistance: the role of nitric oxide and angiotensin II receptors. Vascular health and risk management 5: 73-78, 2009.

34. Brunner F, Doherty AM. Role of ET(B) receptors in local clearance of endothelin-1 in rat heart: studies with the antagonists PD 155080 and BQ-788. FEBS letters 396: 238-242, 1996.

35. Cardoso CG, Jr., Sakai D, Pinto LG, Labes E, de Gusmao JL, Abrahao SB, Tinucci T, Mion D, Jr., da Fonseca AM, Forjaz CL. Neurovascular and hemodynamic responses to hyperinsulinemia in healthy postmenopausal women. Maturitas 58: 50-58, 2007. 
36. Chai W, Liu J, Jahn LA, Fowler DE, Barrett EJ, Liu Z. Salsalate attenuates free fatty acidinduced microvascular and metabolic insulin resistance in humans. Diabetes care 34: 1634-1638, 2011.

37. Chen YL, Messina EJ. Dilation of isolated skeletal muscle arterioles by insulin is endothelium dependent and nitric oxide mediated. The American journal of physiology 270: H2120-2124, 1996.

38. Chisaki K, Okuda Y, Suzuki S, Miyauchi T, Soma M, Ohkoshi N, Sone H, Yamada N, Nakajima T. Eicosapentaenoic acid suppresses basal and insulin-stimulated endothelin-1 production in human endothelial cells. Hypertension research : official journal of the Japanese Society of Hypertension 26: 655-661, 2003.

39. Chiu JD, Richey JM, Harrison LN, Zuniga E, Kolka CM, Kirkman E, Ellmerer M, Bergman RN. Direct administration of insulin into skeletal muscle reveals that the transport of insulin across the capillary endothelium limits the time course of insulin to activate glucose disposal. Diabetes 57: 828-835, 2008.

40. Chobanian AV, Bakris GL, Black HR, Cushman WC, Green LA, Izzo JL, Jr., Jones DW, Materson BJ, Oparil S, Wright JT, Jr., Roccella EJ, National Heart L, Blood Institute Joint National Committee on Prevention DE, Treatment of High Blood P, National High Blood Pressure Education Program Coordinating C. The Seventh Report of the Joint National Committee on 
Prevention, Detection, Evaluation, and Treatment of High Blood Pressure: the JNC 7 report. JAMA : the journal of the American Medical Association 289: 2560-2572, 2003.

41. Chuah YK, Basir R, Talib H, Tie TH, Nordin N. Receptor for Advanced Glycation End Products and Its Involvement in Inflammatory Diseases. International journal of inflammation 2013: 403460, 2013.

42. Clark AD, Barrett EJ, Rattigan S, Wallis MG, Clark MG. Insulin stimulates laser Doppler signal by rat muscle in vivo, consistent with nutritive flow recruitment. Clinical science 100: 283290, 2001.

43. Clark DE, Laeseke PF. Systeme International in the ICU in the United States. Chest 137: 932937, 2010.

44. Clark MG. Impaired microvascular perfusion: a consequence of vascular dysfunction and a potential cause of insulin resistance in muscle. American journal of physiology. Endocrinology and metabolism 295: E732-750, 2008.

45. Cleland SJ, Petrie JR, Ueda S, Elliott HL, Connell JM. Insulin as a vascular hormone: implications for the pathophysiology of cardiovascular disease. Clinical and experimental pharmacology \& physiology 25: 175-184, 1998. 
46. Clerk LH, Vincent MA, Barrett EJ, Lankford MF, Lindner JR. Skeletal muscle capillary responses to insulin are abnormal in late-stage diabetes and are restored by angiotensin-converting enzyme inhibition. American journal of physiology. Endocrinology and metabolism 293: E18041809, 2007.

47. Clerk LH, Vincent MA, Jahn LA, Liu Z, Lindner JR, Barrett EJ. Obesity blunts insulinmediated microvascular recruitment in human forearm muscle. Diabetes 55: 1436-1442, 2006.

48. Clerk LH, Vincent MA, Lindner JR, Clark MG, Rattigan S, Barrett EJ. The vasodilatory actions of insulin on resistance and terminal arterioles and their impact on muscle glucose uptake. Diabetes/metabolism research and reviews 20: 3-12, 2004.

49. Clozel M, Breu V, Burri K, Cassal JM, Fischli W, Gray GA, Hirth G, Loffler BM, Muller M, Neidhart W, et al. Pathophysiological role of endothelin revealed by the first orally active endothelin receptor antagonist. Nature 365: 759-761, 1993.

50. Coggins M, Lindner J, Rattigan S, Jahn L, Fasy E, Kaul S, Barrett E. Physiologic hyperinsulinemia enhances human skeletal muscle perfusion by capillary recruitment. Diabetes 50: 2682-2690, 2001. 
51. d'Uscio LV, Barton M, Shaw S, Luscher TF. Chronic ET(A) receptor blockade prevents endothelial dysfunction of small arteries in apolipoprotein E-deficient mice. Cardiovascular research 53: 487-495, 2002.

52. Davenport AP. International Union of Pharmacology. XXIX. Update on endothelin receptor nomenclature. Pharmacological reviews 54: 219-226, 2002.

53. Davies MG, Hagen PO. Alterations in venous endothelial cell and smooth muscle cell relaxation induced by high glucose concentrations can be prevented by aminoguanidine. The Journal of surgical research 63: 474-479, 1996.

54. Dawson D, Vincent MA, Barrett EJ, Kaul S, Clark A, Leong-Poi H, Lindner JR. Vascular recruitment in skeletal muscle during exercise and hyperinsulinemia assessed by contrast ultrasound. American journal of physiology. Endocrinology and metabolism 282: E714-720, 2002.

55. de Jongh RT, Clark AD, RG IJ, Serne EH, de Vries G, Stehouwer CD. Physiological hyperinsulinaemia increases intramuscular microvascular reactive hyperaemia and vasomotion in healthy volunteers. Diabetologia 47: 978-986, 2004.

56. DeFronzo RA, Ferrannini E. Insulin resistance. A multifaceted syndrome responsible for NIDDM, obesity, hypertension, dyslipidemia, and atherosclerotic cardiovascular disease. Diabetes care 14: 173-194, 1991. 
57. DeFronzo RA, Ferrannini E, Hendler R, Felig P, Wahren J. Regulation of splanchnic and peripheral glucose uptake by insulin and hyperglycemia in man. Diabetes 32: 35-45, 1983.

58. DeFronzo RA, Gunnarsson R, Bjorkman O, Olsson M, Wahren J. Effects of insulin on peripheral and splanchnic glucose metabolism in noninsulin-dependent (type II) diabetes mellitus. The Journal of clinical investigation 76: 149-155, 1985.

59. DeFronzo RA, Tobin JD, Andres R. Glucose clamp technique: a method for quantifying insulin secretion and resistance. The American journal of physiology 237: E214-223, 1979.

60. Disalvo RJ, Bloom WL, Brust AA, Ferguson RW, Ferris EB. A comparison of the metabolic and circulatory effects of epinephrine, nor-epinephrine and insulin hypoglycemia with observations on the influence of autonomic blocking agents. The Journal of clinical investigation 35: 568-577, 1956.

61. Du Bois D, Du Bois EF. A formula to estimate the approximate surface area if height and weight be known. 1916. Nutrition 5: 303-311; discussion 312-303, 1989.

62. Dye AS, Huang H, Bauer JA, Hoffman RP. Hyperglycemia increases muscle blood flow and alters endothelial function in adolescents with type 1 diabetes. Experimental diabetes research 2012: 170380, 2012. 
63. Ebeling P, Koistinen HA, Koivisto VA. Insulin-independent glucose transport regulates insulin sensitivity. FEBS letters 436: 301-303, 1998.

64. Egan BM, Stepniakowski K. Compensatory hyperinsulinemia and the forearm vasodilator response during an oral glucose-tolerance test in obese hypertensives. Journal of hypertension 12: 1061-1067, 1994.

65. Eggleston EM, Jahn LA, Barrett EJ. Hyperinsulinemia rapidly increases human muscle microvascular perfusion but fails to increase muscle insulin clearance: evidence that a saturable process mediates muscle insulin uptake. Diabetes 56: 2958-2963, 2007.

66. Eid HM, Reims H, Arnesen H, Kjeldsen SE, Lyberg T, Seljeflot I. Decreased levels of asymmetric dimethylarginine during acute hyperinsulinemia. Metabolism: clinical and experimental 56: 464-469, 2007.

67. Elshourbagy NA, Korman DR, Wu HL, Sylvester DR, Lee JA, Nuthalaganti P, Bergsma DJ, Kumar CS, Nambi P. Molecular characterization and regulation of the human endothelin receptors. The Journal of biological chemistry 268: 3873-3879, 1993.

68. Eringa EC, Stehouwer CD, van Nieuw Amerongen GP, Ouwehand L, Westerhof N, Sipkema P. Vasoconstrictor effects of insulin in skeletal muscle arterioles are mediated by ERK1/2 
activation in endothelium. American journal of physiology. Heart and circulatory physiology 287: H2043-2048, 2004.

69. Eskens BJ, Mooij HL, Cleutjens JP, Roos JM, Cobelens JE, Vink H, Vanteeffelen JW. Rapid insulin-mediated increase in microvascular glycocalyx accessibility in skeletal muscle may contribute to insulin-mediated glucose disposal in rats. PloS one 8: e55399, 2013.

70. Ferri C, Bellini C, Desideri G, Baldoncini R, Properzi G, Santucci A, De Mattia G. Circulating endothelin-1 levels in obese patients with the metabolic syndrome. Experimental and clinical endocrinology \& diabetes : official journal, German Society of Endocrinology [and] German Diabetes Association 105 Suppl 2: 38-40, 1997.

71. Ferri C, Bellini C, Desideri G, Di Francesco L, Baldoncini R, Santucci A, De Mattia G. Plasma endothelin-1 levels in obese hypertensive and normotensive men. Diabetes 44: 431-436, 1995.

72. Ferri C, Pittoni V, Piccoli A, Laurenti O, Cassone MR, Bellini C, Properzi G, Valesini G, De Mattia G, Santucci A. Insulin stimulates endothelin-1 secretion from human endothelial cells and modulates its circulating levels in vivo. The Journal of clinical endocrinology and metabolism 80: 829-835, 1995. 
73. Ferro CJ, Haynes WG, Hand MF, Webb DJ. Forearm vasoconstriction to endothelin-1 is impaired, but constriction to sarafotoxin $6 \mathrm{c}$ and vasodilatation to BQ-123 unaltered, in patients with essential hypertension. Clinical science 103 Suppl 48: 53S-58S, 2002.

74. Finsnes F, Lyberg T, Christensen G, Skjonsberg OH. Effect of endothelin antagonism on the production of cytokines in eosinophilic airway inflammation. American journal of physiology. Lung cellular and molecular physiology 280: L659-665, 2001.

75. Forstermann U. Nitric oxide and oxidative stress in vascular disease. Pflugers Archiv : European journal of physiology 459: 923-939, 2010.

76. Fujita S, Rasmussen BB, Cadenas JG, Grady JJ, Volpi E. Effect of insulin on human skeletal muscle protein synthesis is modulated by insulin-induced changes in muscle blood flow and amino acid availability. American journal of physiology. Endocrinology and metabolism 291: E745-754, 2006.

77. Fukami K. Structure, regulation, and function of phospholipase C isozymes. Journal of biochemistry 131: 293-299, 2002.

78. Fukami K, Yamagishi SI, Okuda S. Role of AGEs-RAGE system in cardiovascular disease. Current pharmaceutical design, 2013. 
79. Giugliano D, Marfella R, Coppola L, Verrazzo G, Acampora R, Giunta R, Nappo F, Lucarelli C, D'Onofrio F. Vascular effects of acute hyperglycemia in humans are reversed by L-arginine. Evidence for reduced availability of nitric oxide during hyperglycemia. Circulation 95: 1783-1790, 1997.

80. Goodwill AG, Frisbee JC. Oxidant stress and skeletal muscle microvasculopathy in the metabolic syndrome. Vascular pharmacology 57: 150-159, 2012.

81. Groen BB, Hamer HM, Snijders T, van Kranenburg J, Frijns D, Vink H, van Loon LJ. Skeletal muscle capillary density and microvascular function are compromised with aging and type 2 diabetes. Journal of applied physiology 116: 998-1005, 2014.

82. Gudbjornsdottir S, Sjostrand M, Strindberg L, Lonnroth P. Decreased muscle capillary permeability surface area in type 2 diabetic subjects. The Journal of clinical endocrinology and metabolism 90: 1078-1082, 2005.

83. Hamilton-Wessler M, Ader M, Dea MK, Moore D, Loftager M, Markussen J, Bergman RN. Mode of transcapillary transport of insulin and insulin analog NN304 in dog hindlimb: evidence for passive diffusion. Diabetes 51: 574-582, 2002. 
84. Hanley AJ, Williams K, Stern MP, Haffner SM. Homeostasis model assessment of insulin resistance in relation to the incidence of cardiovascular disease: the San Antonio Heart Study. Diabetes care 25: 1177-1184, 2002.

85. Haynes WG, Ferro CJ, O'Kane KP, Somerville D, Lomax CC, Webb DJ. Systemic endothelin receptor blockade decreases peripheral vascular resistance and blood pressure in humans. Circulation 93: 1860-1870, 1996.

86. Haynes WG, Webb DJ. Contribution of endogenous generation of endothelin-1 to basal vascular tone. Lancet 344: 852-854, 1994.

87. Heberlein KR, Straub AC, Isakson BE. The myoendothelial junction: breaking through the matrix? Microcirculation 16: 307-322, 2009.

88. Hedman A, Andersson PE, Reneland R, Lithell HO. Insulin-mediated changes in leg blood flow are coupled to capillary density in skeletal muscle in healthy 70-year-old men. Metabolism: clinical and experimental 50: 1078-1082, 2001.

89. Hilzenrat N, Yaari A, Maislos M, Sikuler E. Splanchnic and systemic hemodynamic effects of sustained euglycemic hyperinsulinemia in rats. Scandinavian journal of clinical and laboratory investigation 61: 383-388, 2001. 
90. Hodnett BL, Hester RL. Regulation of muscle blood flow in obesity. Microcirculation 14: 273288, 2007.

91. Hoffman RP, Sinkey CA, Dopp JM, Phillips BG. Lack of effect of alpha- and beta-adrenergic inhibition on forearm glucose uptake despite differences in forearm blood flow in healthy humans. Metabolism: clinical and experimental 51: 1506-1513, 2002.

92. Honig CR, Odoroff CL, Frierson JL. Capillary recruitment in exercise: rate, extent, uniformity, and relation to blood flow. The American journal of physiology 238: H31-42, 1980.

93. Irving RJ, Noon JP, Watt GC, Webb DJ, Walker BR. Activation of the endothelin system in insulin resistance. QJM : monthly journal of the Association of Physicians 94: 321-326, 2001.

94. Ishibashi KI, Imamura T, Sharma PM, Huang J, Ugi S, Olefsky JM. Chronic endothelin-1 treatment leads to heterologous desensitization of insulin signaling in 3T3-L1 adipocytes. The Journal of clinical investigation 107: 1193-1202, 2001.

95. Isomaa B, Almgren P, Tuomi T, Forsen B, Lahti K, Nissen M, Taskinen MR, Groop L. Cardiovascular morbidity and mortality associated with the metabolic syndrome. Diabetes care 24: 683-689, 2001. 
96. Jandeleit-Dahm K, Watson A, Soro-Paavonen A. The AGE/RAGE axis in diabetes-accelerated atherosclerosis. Clinical and experimental pharmacology \& physiology 35: 329-334, 2008.

97. Kang BY, Kleinhenz JM, Murphy TC, Hart CM. The PPARgamma ligand rosiglitazone attenuates hypoxia-induced endothelin signaling in vitro and in vivo. American journal of physiology. Lung cellular and molecular physiology 301: L881-891, 2011.

98. Kashiwagi A, Shinozaki K, Nishio Y, Maegawa H, Maeno Y, Kanazawa A, Kojima H, Haneda M, Hidaka H, Yasuda H, Kikkawa R. Endothelium-specific activation of NAD(P)H oxidase in aortas of exogenously hyperinsulinemic rats. The American journal of physiology 277: E976-983, 1999.

99. Kashyap SR, Roman LJ, Lamont J, Masters BS, Bajaj M, Suraamornkul S, Belfort R, Berria R, Kellogg DL, Jr., Liu Y, DeFronzo RA. Insulin resistance is associated with impaired nitric oxide synthase activity in skeletal muscle of type 2 diabetic subjects. The Journal of clinical endocrinology and metabolism 90: 1100-1105, 2005.

100. Kashyap SR, Roman LJ, Mandarino L, DeFronzo R, Bajaj M. Hypoadiponectinemia is closely associated with impaired nitric oxide synthase activity in skeletal muscle of type 2 diabetic subjects. Metabolic syndrome and related disorders 8: 459-463, 2010. 
101. Kedzierski RM, Yanagisawa M. Endothelin system: the double-edged sword in health and disease. Annual review of pharmacology and toxicology 41: 851-876, 2001.

102. Kim F, Pham M, Maloney E, Rizzo NO, Morton GJ, Wisse BE, Kirk EA, Chait A, Schwartz MW. Vascular inflammation, insulin resistance, and reduced nitric oxide production precede the onset of peripheral insulin resistance. Arteriosclerosis, thrombosis, and vascular biology 28: 19821988, 2008.

103. Kim JA, Montagnani M, Koh KK, Quon MJ. Reciprocal relationships between insulin resistance and endothelial dysfunction: molecular and pathophysiological mechanisms. Circulation 113: 1888-1904, 2006.

104. King GL. The role of hyperglycaemia and hyperinsulinaemia in causing vascular dysfunction in diabetes. Annals of medicine 28: 427-432, 1996.

105. King GL, Johnson SM. Receptor-mediated transport of insulin across endothelial cells. Science 227: 1583-1586, 1985.

106. Kobayashi M, Olefsky JM. Effect of experimental hyperinsulinemia on insulin binding and glucose transport in isolated rat adipocytes. The American journal of physiology 235: E53-62, 1978. 
107. Krssak M, Brehm A, Bernroider E, Anderwald C, Nowotny P, Dalla Man C, Cobelli C, Cline GW, Shulman GI, Waldhausl W, Roden M. Alterations in postprandial hepatic glycogen metabolism in type 2 diabetes. Diabetes 53: 3048-3056, 2004.

108. Kubota T, Kubota N, Kumagai H, Yamaguchi S, Kozono H, Takahashi T, Inoue M, Itoh S, Takamoto I, Sasako T, Kumagai K, Kawai T, Hashimoto S, Kobayashi T, Sato M, Tokuyama K, Nishimura S, Tsunoda M, Ide T, Murakami K, Yamazaki T, Ezaki O, Kawamura K, Masuda H, Moroi M, Sugi K, Oike Y, Shimokawa H, Yanagihara N, Tsutsui M, Terauchi Y, Tobe K, Nagai R, Kamata K, Inoue K, Kodama T, Ueki K, Kadowaki T. Impaired insulin signaling in endothelial cells reduces insulin-induced glucose uptake by skeletal muscle. Cell metabolism 13: 294-307, 2011.

109. Kuznetsova LV, Tomasek N, Sigurdsson GH, Banic A, Erni D, Wheatley AM. Dissociation between volume blood flow and laser-Doppler signal from rat muscle during changes in vascular tone. The American journal of physiology 274: H1248-1254, 1998.

110. Laakso M, Edelman SV, Brechtel G, Baron AD. Decreased effect of insulin to stimulate skeletal muscle blood flow in obese man. A novel mechanism for insulin resistance. The Journal of clinical investigation 85: 1844-1852, 1990.

111. Laakso M, Edelman SV, Brechtel G, Baron AD. Impaired insulin-mediated skeletal muscle blood flow in patients with NIDDM. Diabetes 41: 1076-1083, 1992. 
112. Laine H, Knuuti MJ, Ruotsalainen U, Raitakari M, Iida H, Kapanen J, Kirvela O, Haaparanta M, Yki-Jarvinen H, Nuutila P. Insulin resistance in essential hypertension is characterized by impaired insulin stimulation of blood flow in skeletal muscle. Journal of hypertension 16: 211219, 1998.

113. Laine H, Yki-Jarvinen H, Kirvela O, Tolvanen T, Raitakari M, Solin O, Haaparanta M, Knuuti J, Nuutila P. Insulin resistance of glucose uptake in skeletal muscle cannot be ameliorated by enhancing endothelium-dependent blood flow in obesity. The Journal of clinical investigation 101: 1156-1162, 1998.

114. Lakka HM, Laaksonen DE, Lakka TA, Niskanen LK, Kumpusalo E, Tuomilehto J, Salonen JT. The metabolic syndrome and total and cardiovascular disease mortality in middle-aged men. JAMA : the journal of the American Medical Association 288: 2709-2716, 2002.

115. Lee JH, Ragolia L. AKT phosphorylation is essential for insulin-induced relaxation of rat vascular smooth muscle cells. American journal of physiology. Cell physiology 291: C1355-1365, 2006.

116. Lincoln TM, Cornwell TL, Taylor AE. cGMP-dependent protein kinase mediates the reduction of $\mathrm{Ca} 2+$ by cAMP in vascular smooth muscle cells. The American journal of physiology 258: C399-407, 1990. 
117. Liu J, Jahn LA, Fowler DE, Barrett EJ, Cao W, Liu Z. Free fatty acids induce insulin resistance in both cardiac and skeletal muscle microvasculature in humans. The Journal of clinical endocrinology and metabolism 96: 438-446, 2011.

118. Loffler BM, Breu V, Clozel M. Effect of different endothelin receptor antagonists and of the novel non-peptide antagonist Ro 46-2005 on endothelin levels in rat plasma. FEBS letters 333: 108-110, 1993.

119. Lott ME, Hogeman C, Herr M, Gabbay R, Sinoway LI. Effects of an oral glucose tolerance test on the myogenic response in healthy individuals. American journal of physiology. Heart and circulatory physiology 292: H304-310, 2007.

120. Lteif A, Vaishnava P, Baron AD, Mather KJ. Endothelin limits insulin action in obese/insulinresistant humans. Diabetes 56: 728-734, 2007.

121. Lteif AA, Han K, Mather KJ. Obesity, insulin resistance, and the metabolic syndrome: determinants of endothelial dysfunction in whites and blacks. Circulation 112: 32-38, 2005.

122. Ludmer PL, Selwyn AP, Shook TL, Wayne RR, Mudge GH, Alexander RW, Ganz P. Paradoxical vasoconstriction induced by acetylcholine in atherosclerotic coronary arteries. The New England journal of medicine 315: 1046-1051, 1986. 
123. Luscher TF, Barton M. Endothelins and endothelin receptor antagonists: therapeutic considerations for a novel class of cardiovascular drugs. Circulation 102: 2434-2440, 2000.

124. Lusis AJ. Atherosclerosis. Nature 407: 233-241, 2000.

125. MacMillan-Crow LA, Crow JP, Kerby JD, Beckman JS, Thompson JA. Nitration and inactivation of manganese superoxide dismutase in chronic rejection of human renal allografts. Proceedings of the National Academy of Sciences of the United States of America 93: 11853$11858,1996$.

126. Madonna R, De Caterina R. Prolonged exposure to high insulin impairs the endothelial PI3kinase/Akt/nitric oxide signalling. Thrombosis and haemostasis 101: 345-350, 2009.

127. Makimattila S, Yki-Jarvinen H. Endothelial dysfunction in human diabetes. Current diabetes reports 2: 26-36, 2002.

128. Martin C, Desai KS, Steiner G. Receptor and postreceptor insulin resistance induced by in vivo hyperinsulinemia. Canadian journal of physiology and pharmacology 61: 802-807, 1983.

129. Mather K, Anderson TJ, Verma S. Insulin action in the vasculature: physiology and pathophysiology. Journal of vascular research 38: 415-422, 2001. 
130. Mather KJ, Lteif A, Steinberg HO, Baron AD. Interactions between endothelin and nitric oxide in the regulation of vascular tone in obesity and diabetes. Diabetes 53: 2060-2066, 2004.

131. Mather KJ, Mirzamohammadi B, Lteif A, Steinberg HO, Baron AD. Endothelin contributes to basal vascular tone and endothelial dysfunction in human obesity and type 2 diabetes. Diabetes 51: 3517-3523, 2002.

132. Mazzuca MQ, Khalil RA. Vascular endothelin receptor type B: structure, function and dysregulation in vascular disease. Biochemical pharmacology 84: 147-162, 2012.

133. McNair LL, Salamanca DA, Khalil RA. Endothelin-1 promotes Ca2+ antagonist-insensitive coronary smooth muscle contraction via activation of epsilon-protein kinase C. Hypertension 43: 897-904, 2004.

134. Meerwaldt R, Graaff R, Oomen PH, Links TP, Jager JJ, Alderson NL, Thorpe SR, Baynes JW, Gans RO, Smit AJ. Simple non-invasive assessment of advanced glycation endproduct accumulation. Diabetologia 47: 1324-1330, 2004.

135. Meijer RI, De Boer MP, Groen MR, Eringa EC, Rattigan S, Barrett EJ, Smulders YM, Serne EH. Insulin-induced microvascular recruitment in skin and muscle are related and both are associated with whole-body glucose uptake. Microcirculation 19: 494-500, 2012. 
136. Miyauchi T, Masaki T. Pathophysiology of endothelin in the cardiovascular system. Annual review of physiology 61: 391-415, 1999.

137. Molero L, Farre J, Garcia-Mendez A, Jimenez Mateos-Caceres P, Carrasco Martin C, Millas I, Navarro F, Cordoba M, Casado S, Lopez-Farre A. Endothelin-1 induced proinflammatory markers in the myocardium and leukocytes of guinea-pigs: role of glycoprotein IIB/IIIA receptors. Cardiovascular research 57: 109-118, 2003.

138. Montagnani M, Chen H, Barr VA, Quon MJ. Insulin-stimulated activation of eNOS is independent of $\mathrm{Ca} 2+$ but requires phosphorylation by Akt at Ser(1179). The Journal of biological chemistry 276: 30392-30398, 2001.

139. Montagnani M, Golovchenko I, Kim I, Koh GY, Goalstone ML, Mundhekar AN, Johansen M, Kucik DF, Quon MJ, Draznin B. Inhibition of phosphatidylinositol 3-kinase enhances mitogenic actions of insulin in endothelial cells. The Journal of biological chemistry 277: 17941799, 2002.

140. Montagnani M, Ravichandran LV, Chen H, Esposito DL, Quon MJ. Insulin receptor substrate-1 and phosphoinositide-dependent kinase-1 are required for insulin-stimulated production of nitric oxide in endothelial cells. Molecular endocrinology 16: 1931-1942, 2002. 
141. Morgantini C, Stea F, Boldrini B, Duranti E, Ghiadoni L, Natali A. Effect of mild hyperisulinemia on conduit vessel endothelial function: role of noradrenergic activation. Journal of hypertension 30: 720-724, 2012.

142. Mulder AH, van Dijk AP, Smits P, Tack CJ. Real-time contrast imaging: a new method to monitor capillary recruitment in human forearm skeletal muscle. Microcirculation 15: 203-213, 2008.

143. Muniyappa R, Karne RJ, Hall G, Crandon SK, Bronstein JA, Ver MR, Hortin GL, Quon MJ. Oral glucosamine for 6 weeks at standard doses does not cause or worsen insulin resistance or endothelial dysfunction in lean or obese subjects. Diabetes 55: 3142-3150, 2006.

144. Muniyappa R, Montagnani M, Koh KK, Quon MJ. Cardiovascular actions of insulin. Endocrine reviews 28: 463-491, 2007.

145. Murdolo G, Sjostrand M, Strindberg L, Gudbjornsdottir S, Lind L, Lonnroth P, Jansson PA. Effects of Intrabrachial metacholine infusion on muscle capillary recruitment and forearm glucose uptake during physiological hyperinsulinemia in obese, insulin-resistant individuals. The Journal of clinical endocrinology and metabolism 93: 2764-2773, 2008. 
146. Murphy RA, Walker JS. Inhibitory mechanisms for cross-bridge cycling: the nitric oxidecGMP signal transduction pathway in smooth muscle relaxation. Acta physiologica Scandinavica 164: 373-380, 1998.

147. Myung SC, Keum EM, Park SY, Lee MY, Kim SC. Vasomotor action of insulin on the rabbit normal cavernous smooth muscle. European journal of pharmacology 536: 142-147, 2006.

148. Natali A, Quinones Galvan A, Pecori N, Sanna G, Toschi E, Ferrannini E. Vasodilation with sodium nitroprusside does not improve insulin action in essential hypertension. Hypertension 31: 632-636, 1998.

149. Natali A, Toschi E, Baldeweg S, Ciociaro D, Favilla S, Sacca L, Ferrannini E. Clustering of insulin resistance with vascular dysfunction and low-grade inflammation in type 2 diabetes. Diabetes 55: 1133-1140, 2006.

150. Nava P, Collados MT, Masso F, Guarner V. Endothelin mediation of insulin and glucoseinduced changes in vascular contractility. Hypertension 30: 825-829, 1997.

151. Newman JM, Ross RM, Richards SM, Clark MG, Rattigan S. Insulin and contraction increase nutritive blood flow in rat muscle in vivo determined by microdialysis of L-[14C]glucose. The Journal of physiology 585: 217-229, 2007. 
152. Nieuwdorp M, Meuwese MC, Vink H, Hoekstra JB, Kastelein JJ, Stroes ES. The endothelial glycocalyx: a potential barrier between health and vascular disease. Current opinion in lipidology 16: 507-511, 2005.

153. Nishikibe M, Tsuchida S, Okada M, Fukuroda T, Shimamoto K, Yano M, Ishikawa K, Ikemoto F. Antihypertensive effect of a newly synthesized endothelin antagonist, BQ-123, in a genetic hypertensive model. Life sciences 52: 717-724, 1993.

154. Nitenberg A, Cosson E, Pham I. Postprandial endothelial dysfunction: role of glucose, lipids and insulin. Diabetes \& metabolism 32 Spec No2: 2S28-33, 2006.

155. Nuutila P, Raitakari M, Laine H, Kirvela O, Takala T, Utriainen T, Makimattila S, Pitkanen OP, Ruotsalainen U, Iida H, Knuuti J, Yki-Jarvinen H. Role of blood flow in regulating insulinstimulated glucose uptake in humans. Studies using bradykinin, [15O]water, and [18F]fluorodeoxy-glucose and positron emission tomography. The Journal of clinical investigation 97: 1741$1747,1996$.

156. Nystrom T, Gutniak MK, Zhang Q, Zhang F, Holst JJ, Ahren B, Sjoholm A. Effects of glucagon-like peptide-1 on endothelial function in type 2 diabetes patients with stable coronary artery disease. American journal of physiology. Endocrinology and metabolism 287: E1209-1215, 2004. 
157. Okubo K, Kushiro T, Takahashi A, Kanmatsuse K. [Role of endothelium-derived hyperpolarizing factor in insulin-induced vasodilation in rat mesenteric artery]. Nihon Jinzo Gakkai shi 41: 685-691, 1999.

158. Olsen DB, Sacchetti M, Dela F, Ploug T, Saltin B. Glucose clearance is higher in arm than leg muscle in type 2 diabetes. The Journal of physiology 565: 555-562, 2005.

159. Pashkow FJ. Oxidative Stress and Inflammation in Heart Disease: Do Antioxidants Have a Role in Treatment and/or Prevention? International journal of inflammation 2011: 514623, 2011.

160. Pate M, Damarla V, Chi DS, Negi S, Krishnaswamy G. Endothelial cell biology: role in the inflammatory response. Advances in clinical chemistry 52: 109-130, 2010.

161. Petersen KF, Dufour S, Savage DB, Bilz S, Solomon G, Yonemitsu S, Cline GW, Befroy D, Zemany L, Kahn BB, Papademetris X, Rothman DL, Shulman GI. The role of skeletal muscle insulin resistance in the pathogenesis of the metabolic syndrome. Proceedings of the National Academy of Sciences of the United States of America 104: 12587-12594, 2007.

162. Phillips SA. Arterial stiffness and type 2 diabetes: dietary modulation after a single meal? Hypertension research : official journal of the Japanese Society of Hypertension 33: 666-667, 2010. 
163. Pierce KL, Premont RT, Lefkowitz RJ. Seven-transmembrane receptors. Nature reviews. Molecular cell biology 3: 639-650, 2002.

164. Potenza MA, Marasciulo FL, Chieppa DM, Brigiani GS, Formoso G, Quon MJ, Montagnani M. Insulin resistance in spontaneously hypertensive rats is associated with endothelial dysfunction characterized by imbalance between NO and ET-1 production. American journal of physiology. Heart and circulatory physiology 289: H813-822, 2005.

165. Potenza MA, Marasciulo FL, Tarquinio M, Quon MJ, Montagnani M. Treatment of spontaneously hypertensive rats with rosiglitazone and/or enalapril restores balance between vasodilator and vasoconstrictor actions of insulin with simultaneous improvement in hypertension and insulin resistance. Diabetes 55: 3594-3603, 2006.

166. Quinones MJ, Hernandez-Pampaloni M, Schelbert H, Bulnes-Enriquez I, Jimenez X, Hernandez G, De La Rosa R, Chon Y, Yang H, Nicholas SB, Modilevsky T, Yu K, Van Herle K, Castellani LW, Elashoff R, Hsueh WA. Coronary vasomotor abnormalities in insulin-resistant individuals. Annals of internal medicine 140: 700-708, 2004.

167. Qvisth V, Hagstrom-Toft E, Moberg E, Sjoberg S, Bolinder J. Lactate release from adipose tissue and skeletal muscle in vivo: defective insulin regulation in insulin-resistant obese women. American journal of physiology. Endocrinology and metabolism 292: E709-714, 2007. 
168. Radegran G. Limb and skeletal muscle blood flow measurements at rest and during exercise in human subjects. The Proceedings of the Nutrition Society 58: 887-898, 1999.

169. Raitakari M, Knuuti MJ, Ruotsalainen U, Laine H, Makea P, Teras M, Sipila H, Niskanen T, Raitakari OT, Iida H, et al. Insulin increases blood volume in human skeletal muscle: studies using [15O]CO and positron emission tomography. The American journal of physiology 269: E1000$1005,1995$.

170. Raitakari M, Nuutila P, Knuuti J, Raitakari OT, Laine H, Ruotsalainen U, Kirvela O, Takala TO, Iida H, Yki-Jarvinen H. Effects of insulin on blood flow and volume in skeletal muscle of patients with IDDM: studies using [15O]H2O, [15O]CO, and positron emission tomography. Diabetes 46: 2017-2021, 1997.

171. Rask-Madsen C, King GL. Endothelium-dependent delivery of insulin to muscle interstitium. Cell metabolism 13: 236-238, 2011.

172. Rask-Madsen C, Li Q, Freund B, Feather D, Abramov R, Wu IH, Chen K, YamamotoHiraoka J, Goldenbogen J, Sotiropoulos KB, Clermont A, Geraldes P, Dall'Osso C, Wagers AJ, Huang PL, Rekhter M, Scalia R, Kahn CR, King GL. Loss of insulin signaling in vascular endothelial cells accelerates atherosclerosis in apolipoprotein E null mice. Cell metabolism 11: 379-389, 2010. 
173. Rattigan S, Clark MG, Barrett EJ. Hemodynamic actions of insulin in rat skeletal muscle: evidence for capillary recruitment. Diabetes 46: 1381-1388, 1997.

174. Reaven GM. Insulin resistance: the link between obesity and cardiovascular disease. The Medical clinics of North America 95: 875-892, 2011.

175. Rennings AJ, Smits P, Stewart MW, Tack CJ. Fluid retention and vascular effects of rosiglitazone in obese, insulin-resistant, nondiabetic subjects. Diabetes care 29: 581-587, 2006.

176. Roden M. Clinical Diabetes Research: Methods and Techniques. edn. Wiley, 2007.

177. Rongen GA, Smits P, Ver Donck K, Willemsen JJ, De Abreu RA, Van Belle H, Thien T. Hemodynamic and neurohumoral effects of various grades of selective adenosine transport inhibition in humans. Implications for its future role in cardioprotection. The Journal of clinical investigation 95: 658-668, 1995.

178. Rosdahl H, Lind L, Millgard J, Lithell H, Ungerstedt U, Henriksson J. Effect of physiological hyperinsulinemia on blood flow and interstitial glucose concentration in human skeletal muscle and adipose tissue studied by microdialysis. Diabetes 47: 1296-1301, 1998.

179. Ross RM, Kolka CM, Rattigan S, Clark MG. Acute blockade by endothelin-1 of haemodynamic insulin action in rats. Diabetologia 50: 443-451, 2007. 
180. Rowe JW, Young JB, Minaker KL, Stevens AL, Pallotta J, Landsberg L. Effect of insulin and glucose infusions on sympathetic nervous system activity in normal man. Diabetes 30: 219-225, 1981.

181. Roy D, Perreault M, Marette A. Insulin stimulation of glucose uptake in skeletal muscles and adipose tissues in vivo is NO dependent. The American journal of physiology 274: E692-699, 1998.

182. Ruiz-Torres A, Lozano R, Melon J, Carraro R. On how insulin may influence ageing and become atherogenic throughout the insulin-like growth factor-1 receptor pathway: in vitro studies with human vascular smooth muscle cells. Gerontology 51: 225-230, 2005.

183. Ryan AS. Insulin resistance with aging: effects of diet and exercise. Sports medicine 30: 327346, 2000.

184. Sanchez-Margalet V, Goldfine ID, Vlahos CJ, Sung CK. Role of phosphatidylinositol-3kinase in insulin receptor signaling: studies with inhibitor, LY294002. Biochemical and biophysical research communications 204: 446-452, 1994.

185. Sanchez A, Martinez P, Munoz M, Benedito S, Garcia-Sacristan A, Hernandez M, Prieto D. Endothelin-1 contributes to endothelial dysfunction and enhanced vasoconstriction through 
augmented superoxide production in penile arteries from insulin resistant obese rats: role of ET and ET receptors. British journal of pharmacology, 2014.

186. Sandqvist M, Strindberg L, Schmelz M, Lonnroth P, Jansson PA. Impaired delivery of insulin to adipose tissue and skeletal muscle in obese women with postprandial hyperglycemia. The Journal of clinical endocrinology and metabolism 96: E1320-1324, 2011.

187. Sauder MA, Liu J, Jahn LA, Fowler DE, Chai W, Liu Z. Candesartan acutely recruits skeletal and cardiac muscle microvasculature in healthy humans. The Journal of clinical endocrinology and metabolism 97: E1208-1212, 2012.

188. Sausbier M, Schubert R, Voigt V, Hirneiss C, Pfeifer A, Korth M, Kleppisch T, Ruth P, Hofmann F. Mechanisms of NO/cGMP-dependent vasorelaxation. Circulation research 87: 825$830,2000$.

189. Scheede-Bergdahl C, Olsen DB, Reving D, Boushel R, Dela F. Insulin and non-insulin mediated vasodilation and glucose uptake in patients with type 2 diabetes. Diabetes research and clinical practice 85: 243-251, 2009.

190. Scherrer U, Randin D, Vollenweider P, Vollenweider L, Nicod P. Nitric oxide release accounts for insulin's vascular effects in humans. The Journal of clinical investigation 94: 2511$2515,1994$. 
191. Scherrer U, Sartori C. Insulin as a vascular and sympathoexcitatory hormone: implications for blood pressure regulation, insulin sensitivity, and cardiovascular morbidity. Circulation 96: 4104-4113, 1997.

192. Scherrer U, Vollenweider P, Randin D, Jequier E, Nicod P, Tappy L. Suppression of insulininduced sympathetic activation and vasodilation by dexamethasone in humans. Circulation $\mathbf{8 8}$ : 388-394, 1993.

193. Schmidt AM, Stern D. Atherosclerosis and diabetes: the RAGE connection. Current atherosclerosis reports 2: 430-436, 2000.

194. Serne EH, de Jongh RT, Eringa EC, RG IJ, Stehouwer CD. Microvascular dysfunction: a potential pathophysiological role in the metabolic syndrome. Hypertension 50: 204-211, 2007.

195. Shaw SG, Boden PJ. Insulin resistance, obesity and the metabolic syndrome. Is there a therapeutic role for endothelin-1 antagonists? Current vascular pharmacology 3: 359-363, 2005.

196. Shemyakin A, Bohm F, Wagner H, Efendic S, Bavenholm P, Pernow J. Enhanced endothelium-dependent vasodilatation by dual endothelin receptor blockade in individuals with insulin resistance. Journal of cardiovascular pharmacology 47: 385-390, 2006. 
197. Shemyakin A, Salehzadeh F, Bohm F, Al-Khalili L, Gonon A, Wagner H, Efendic S, Krook A, Pernow J. Regulation of glucose uptake by endothelin-1 in human skeletal muscle in vivo and in vitro. The Journal of clinical endocrinology and metabolism 95: 2359-2366, 2010.

198. Shoemaker JK, Bonen A. Vascular actions of insulin in health and disease. Canadian journal of applied physiology = Revue canadienne de physiologie appliquee 20: 127-154, 1995.

199. Singhal P, Caumo A, Carey PE, Cobelli C, Taylor R. Regulation of endogenous glucose production after a mixed meal in type 2 diabetes. American journal of physiology. Endocrinology and metabolism 283: E275-283, 2002.

200. Sjoberg KA, Rattigan S, Hiscock N, Richter EA, Kiens B. A new method to study changes in microvascular blood volume in muscle and adipose tissue: real-time imaging in humans and rat. American journal of physiology. Heart and circulatory physiology 301: H450-458, 2011.

201. Sjostrand M, Gudbjornsdottir S, Holmang A, Lonn L, Strindberg L, Lonnroth P. Delayed transcapillary transport of insulin to muscle interstitial fluid in obese subjects. Diabetes 51: 2742$2748,2002$.

202. Solomon TP, Haus JM, Li Y, Kirwan JP. Progressive hyperglycemia across the glucose tolerance continuum in older obese adults is related to skeletal muscle capillarization and nitric oxide bioavailability. The Journal of clinical endocrinology and metabolism 96: 1377-1384, 2011. 
203. Sonne MP, Alibegovic AC, Hojbjerre L, Vaag A, Stallknecht B, Dela F. Effect of 10 days of bedrest on metabolic and vascular insulin action: a study in individuals at risk for type 2 diabetes. Journal of applied physiology 108: 830-837, 2010.

204. Sonne MP, Hojbjerre L, Alibegovic AC, Vaag A, Stallknecht B, Dela F. Diminished insulinmediated forearm blood flow and muscle glucose uptake in young men with low birth weight. Journal of vascular research 47: 139-147, 2010.

205. Stankova J, D'Orleans-Juste P, Rola-Pleszczynski M. ET-1 induces IL-6 gene expression in human umbilical vein endothelial cells: synergistic effect of IL-1. The American journal of physiology 271: C1073-1078, 1996.

206. Stehouwer CD, Henry RM, Ferreira I. Arterial stiffness in diabetes and the metabolic syndrome: a pathway to cardiovascular disease. Diabetologia 51: 527-539, 2008.

207. Steil GM, Ader M, Moore DM, Rebrin K, Bergman RN. Transendothelial insulin transport is not saturable in vivo. No evidence for a receptor-mediated process. The Journal of clinical investigation 97: 1497-1503, 1996. 
208. Steinberg HO, Brechtel G, Johnson A, Fineberg N, Baron AD. Insulin-mediated skeletal muscle vasodilation is nitric oxide dependent. A novel action of insulin to increase nitric oxide release. The Journal of clinical investigation 94: 1172-1179, 1994.

209. Steinberg HO, Chaker H, Leaming R, Johnson A, Brechtel G, Baron AD. Obesity/insulin resistance is associated with endothelial dysfunction. Implications for the syndrome of insulin resistance. The Journal of clinical investigation 97: 2601-2610, 1996.

210. Steinberg HO, Paradisi G, Hook G, Crowder K, Cronin J, Baron AD. Free fatty acid elevation impairs insulin-mediated vasodilation and nitric oxide production. Diabetes 49: 1231-1238, 2000.

211. Steinberg HO, Tarshoby M, Monestel R, Hook G, Cronin J, Johnson A, Bayazeed B, Baron AD. Elevated circulating free fatty acid levels impair endothelium-dependent vasodilation. The Journal of clinical investigation 100: 1230-1239, 1997.

212. Stern DM, Yan SD, Yan SF, Schmidt AM. Receptor for advanced glycation endproducts (RAGE) and the complications of diabetes. Ageing research reviews 1: 1-15, 2002.

213. Straub AC, Butcher JT, Billaud M, Mutchler SM, Artamonov MV, Nguyen AT, Johnson T, Best AK, Miller MP, Palmer LA, Columbus L, Somlyo AV, Le TH, Isakson BE. Hemoglobin alpha/eNOS Coupling at Myoendothelial Junctions Is Required for Nitric Oxide Scavenging During Vasoconstriction. Arteriosclerosis, thrombosis, and vascular biology, 2014. 
214. Straub AC, Lohman AW, Billaud M, Johnstone SR, Dwyer ST, Lee MY, Bortz PS, Best AK, Columbus L, Gaston B, Isakson BE. Endothelial cell expression of haemoglobin alpha regulates nitric oxide signalling. Nature 491: 473-477, 2012.

215. Straub AC, Zeigler AC, Isakson BE. The myoendothelial junction: connections that deliver the message. Physiology 29: 242-249, 2014.

216. Strawbridge AB, Elmendorf JS. Phosphatidylinositol 4,5-bisphosphate reverses endothelin1-induced insulin resistance via an actin-dependent mechanism. Diabetes 54: 1698-1705, 2005.

217. Subaran SC, Sauder MA, Chai W, Jahn LA, Fowler DE, Aylor KW, Basu A, Liu Z. GLP-1 at physiological concentrations recruits skeletal and cardiac muscle microvasculature in healthy humans. Clinical science 127: 163-170, 2014.

218. Sun XJ, Miralpeix M, Myers MG, Jr., Glasheen EM, Backer JM, Kahn CR, White MF. Expression and function of IRS-1 in insulin signal transmission. The Journal of biological chemistry 267: 22662-22672, 1992.

219. Tack CJ, Heeremans M, Thien T, Lutterman JA, Smits P. Regional hyperinsulinemia induces vasodilation but does not modulate adrenergic responsiveness in humans. Journal of cardiovascular pharmacology 28: 245-251, 1996. 
220. Tack CJ, Lutterman JA, Vervoort G, Thien T, Smits P. Activation of the sodium-potassium pump contributes to insulin-induced vasodilation in humans. Hypertension 28: 426-432, 1996.

221. Tack CJ, Ong MK, Lutterman JA, Smits P. Insulin-induced vasodilatation and endothelial function in obesity/insulin resistance. Effects of troglitazone. Diabetologia 41: 569-576, 1998.

222. Takahashi K, Ghatei MA, Lam HC, O'Halloran DJ, Bloom SR. Elevated plasma endothelin in patients with diabetes mellitus. Diabetologia 33: 306-310, 1990.

223. Tarbell JM, Ebong EE. The endothelial glycocalyx: a mechano-sensor and -transducer. Science signaling 1: pt8, 2008.

224. Tesauro M, Cardillo C. Obesity, blood vessels and metabolic syndrome. Acta physiologica 203: 279-286, 2011.

225. Tesfamariam B, Brown ML, Deykin D, Cohen RA. Elevated glucose promotes generation of endothelium-derived vasoconstrictor prostanoids in rabbit aorta. The Journal of clinical investigation 85: 929-932, 1990.

226. Tesfamariam B, Cohen RA. Free radicals mediate endothelial cell dysfunction caused by elevated glucose. The American journal of physiology 263: H321-326, 1992. 
227. Tessari P, Cecchet D, Cosma A, Vettore M, Coracina A, Millioni R, Iori E, Puricelli L, Avogaro A, Vedovato M. Nitric oxide synthesis is reduced in subjects with type 2 diabetes and nephropathy. Diabetes 59: 2152-2159, 2010.

228. Tessari P, Coracina A, Puricelli L, Vettore M, Cosma A, Millioni R, Cecchet D, Avogaro A, Tiengo A, Kiwanuka E. Acute effect of insulin on nitric oxide synthesis in humans: a precursorproduct isotopic study. American journal of physiology. Endocrinology and metabolism 293: E776-782, 2007.

229. Timmerman KL, Lee JL, Fujita S, Dhanani S, Dreyer HC, Fry CS, Drummond MJ, SheffieldMoore M, Rasmussen BB, Volpi E. Pharmacological vasodilation improves insulin-stimulated muscle protein anabolism but not glucose utilization in older adults. Diabetes 59: 2764-2771, 2010.

230. Trovati M, Anfossi G. Influence of insulin and of insulin resistance on platelet and vascular smooth muscle cell function. Journal of diabetes and its complications 16: 35-40, 2002.

231. Tsukahara H, Kikuchi K, Tsumura K, Kimura K, Hata I, Hiraoka M, Sudo M. Experimentally induced acute hyperinsulinemia stimulates endogenous nitric oxide production in humans: detection using urinary NO2-/NO3-excretion. Metabolism: clinical and experimental 46: 406-409, 1997. 
232. Urschel KL, Escobar J, McCutcheon LJ, Geor RJ. Effects of the rate of insulin infusion during isoglycemic, hyperinsulinemic clamp procedures on measures of insulin action in healthy, mature thoroughbred mares. Domestic animal endocrinology 47: 83-91, 2014.

233. Utriainen T, Malmstrom R, Makimattila S, Yki-Jarvinen H. Methodological aspects, doseresponse characteristics and causes of interindividual variation in insulin stimulation of limb blood flow in normal subjects. Diabetologia 38: 555-564, 1995.

234. Utriainen T, Nuutila $P$, Takala T, Vicini $P$, Ruotsalainen U, Ronnemaa T, Tolvanen $T$, Raitakari M, Haaparanta M, Kirvela O, Cobelli C, Yki-Jarvinen H. Intact insulin stimulation of skeletal muscle blood flow, its heterogeneity and redistribution, but not of glucose uptake in noninsulin-dependent diabetes mellitus. The Journal of clinical investigation 100: 777-785, 1997.

235. van Gurp PJ, Rongen GA, Lenders JW, Al Nabawy AK, Timmers HJ, Tack CJ. Sustained hyperglycaemia increases muscle blood flow but does not affect sympathetic activity in resting humans. European journal of applied physiology 93: 648-654, 2005.

236. van Veen S, Frolich M, Chang PC. Acute hyperglycaemia in the forearm induces vasodilation that is not modified by hyperinsulinaemia. Journal of human hypertension 13: 263-268, 1999.

237. Veniant M, Clozel JP, Hess P, Clozel M. Endothelin plays a role in the maintenance of blood pressure in normotensive guinea pigs. Life sciences 55: 445-454, 1994. 
238. Verhaar MC, Strachan FE, Newby DE, Cruden NL, Koomans HA, Rabelink TJ, Webb DJ. Endothelin-A receptor antagonist-mediated vasodilatation is attenuated by inhibition of nitric oxide synthesis and by endothelin-B receptor blockade. Circulation 97: 752-756, 1998.

239. Vicent D, Ilany J, Kondo T, Naruse K, Fisher SJ, Kisanuki YY, Bursell S, Yanagisawa M, King GL, Kahn CR. The role of endothelial insulin signaling in the regulation of vascular tone and insulin resistance. The Journal of clinical investigation 111: 1373-1380, 2003.

240. Vincent MA, Barrett EJ, Lindner JR, Clark MG, Rattigan S. Inhibiting NOS blocks microvascular recruitment and blunts muscle glucose uptake in response to insulin. American journal of physiology. Endocrinology and metabolism 285: E123-129, 2003.

241. Vincent MA, Clerk LH, Lindner JR, Klibanov AL, Clark MG, Rattigan S, Barrett EJ. Microvascular recruitment is an early insulin effect that regulates skeletal muscle glucose uptake in vivo. Diabetes 53: 1418-1423, 2004.

242. Vincent MA, Dawson D, Clark AD, Lindner JR, Rattigan S, Clark MG, Barrett EJ. Skeletal muscle microvascular recruitment by physiological hyperinsulinemia precedes increases in total blood flow. Diabetes 51: 42-48, 2002. 
243. Virdis A, Neves MF, Duranti E, Bernini G, Taddei S. Microvascular endothelial dysfunction in obesity and hypertension. Current pharmaceutical design 19: 2382-2389, 2013.

244. Vollenweider P, Randin D, Tappy L, Jequier E, Nicod P, Scherrer U. Impaired insulininduced sympathetic neural activation and vasodilation in skeletal muscle in obese humans. The Journal of clinical investigation 93: 2365-2371, 1994.

245. Vollenweider P, Tappy L, Randin D, Schneiter P, Jequier E, Nicod P, Scherrer U. Differential effects of hyperinsulinemia and carbohydrate metabolism on sympathetic nerve activity and muscle blood flow in humans. The Journal of clinical investigation 92: 147-154, 1993.

246. Wagner OF, Christ G, Wojta J, Vierhapper H, Parzer S, Nowotny PJ, Schneider B, Waldhausl W, Binder BR. Polar secretion of endothelin-1 by cultured endothelial cells. The Journal of biological chemistry 267: 16066-16068, 1992.

247. Wang H, Wang AX, Liu Z, Barrett EJ. Insulin signaling stimulates insulin transport by bovine aortic endothelial cells. Diabetes 57: 540-547, 2008.

248. Wang Y, Zeng FH, Long CL, Pan ZY, Cui WY, Wang RH, Liu GS, Wang H. The novel ATPsensitive potassium channel opener iptakalim prevents insulin resistance associated with hypertension via restoring endothelial function. Acta pharmacologica Sinica 32: 1466-1474, 2011. 
249. Wedgwood S, McMullan DM, Bekker JM, Fineman JR, Black SM. Role for endothelin-1induced superoxide and peroxynitrite production in rebound pulmonary hypertension associated with inhaled nitric oxide therapy. Circulation research 89: 357-364, 2001.

250. Weil BR, Westby CM, Greiner JJ, Stauffer BL, DeSouza CA. Elevated endothelin-1 vasoconstrictor tone in prehypertensive adults. The Canadian journal of cardiology 28: 347-353, 2012.

251. Wheatley CM, Rattigan S, Richards SM, Barrett EJ, Clark MG. Skeletal muscle contraction stimulates capillary recruitment and glucose uptake in insulin-resistant obese Zucker rats. American journal of physiology. Endocrinology and metabolism 287: E804-809, 2004.

252. Wiberg B, Sundstrom J, Zethelius B, Lind L. Insulin sensitivity measured by the euglycaemic insulin clamp and proinsulin levels as predictors of stroke in elderly men. Diabetologia 52: 90-96, 2009.

253. Wilson SH, Simari RD, Lerman A. The effect of endothelin-1 on nuclear factor kappa B in macrophages. Biochemical and biophysical research communications 286: 968-972, 2001.

254. Wimalasundera RC, Mc GTSA, Regan L, Hughes AD. Action of the endothelin receptor (ETA) antagonist BQ-123 on forearm blood flow in young normotensive subjects. Clinical science 102: 661-666, 2002. 
255. Xu L, Badr MZ. Enhanced potential for oxidative stress in hyperinsulinemic rats: imbalance between hepatic peroxisomal hydrogen peroxide production and decomposition due to hyperinsulinemia. Hormone and metabolic research $=$ Hormon- und Stoffwechselforschung $=$ Hormones et metabolisme 31: 278-282, 1999.

256. Yamagishi S, Imaizumi T. Diabetic vascular complications: pathophysiology, biochemical basis and potential therapeutic strategy. Current pharmaceutical design 11: 2279-2299, 2005.

257. Yamagishi S, Matsui T, Ueda S, Nakamura K, Imaizumi T. Advanced glycation end products (AGEs) and cardiovascular disease (CVD) in diabetes. Cardiovascular \& hematological agents in medicinal chemistry 5: 236-240, 2007.

258. Yamagishi S, Nakamura K, Matsui T, Ueda S, Noda Y, Imaizumi T. Inhibitors of advanced glycation end products (AGEs): potential utility for the treatment of cardiovascular disease. Cardiovascular therapeutics 26: 50-58, 2008.

259. Yamagishi S, Nakamura K, Takeuchi M, Imaizumi T. Molecular mechanism for accelerated atherosclerosis in diabetes and its potential therapeutic intervention. International journal of clinical pharmacology research 24: 129-134, 2004. 
260. Young CN, Deo SH, Chaudhary K, Thyfault JP, Fadel PJ. Insulin enhances the gain of arterial baroreflex control of muscle sympathetic nerve activity in humans. The Journal of physiology $\mathbf{5 8 8}$ : 3593-3603, 2010.

261. Zavaroni I, Platti PM, Monti LD, Gasparini P, Barilli LA, Massironi P, Ardigo D, Valsecchi G, Delsignore R, Reaven GM. Plasma nitric oxide concentrations are elevated in insulin-resistant healthy subjects. Metabolism: clinical and experimental 49: 959-961, 2000.

262. Zeng G, Nystrom FH, Ravichandran LV, Cong LN, Kirby M, Mostowski H, Quon MJ. Roles for insulin receptor, PI3-kinase, and Akt in insulin-signaling pathways related to production of nitric oxide in human vascular endothelial cells. Circulation 101: 1539-1545, 2000.

263. Zeng G, Quon MJ. Insulin-stimulated production of nitric oxide is inhibited by wortmannin. Direct measurement in vascular endothelial cells. The Journal of clinical investigation 98: 894898, 1996.

264. Zethelius B, Lithell H, Hales CN, Berne C. Insulin sensitivity, proinsulin and insulin as predictors of coronary heart disease. A population-based 10-year, follow-up study in 70-year old men using the euglycaemic insulin clamp. Diabetologia 48: 862-867, 2005.

265. Zhang L, Vincent MA, Richards SM, Clerk LH, Rattigan S, Clark MG, Barrett EJ. Insulin sensitivity of muscle capillary recruitment in vivo. Diabetes 53: 447-453, 2004. 
Table 1. Effects of hyperinsulinemia on conduit vessel blood flow in healthy individuals.

\begin{tabular}{|c|c|c|c|c|c|c|c|c|}
\hline Author & $\mathbf{N}$ & $\begin{array}{c}\text { Insulin dose } \\
(\mathrm{mU} / \mathrm{kg} / \mathrm{min})\end{array}$ & $\begin{array}{c}\text { Insulin } \\
\text { duration (min) }\end{array}$ & $\overline{\operatorname{Age}(y)}$ & BMI $\left(\mathrm{kg} / \mathrm{m}^{2}\right)$ & Endpoint & Outcome & Method \\
\hline \multicolumn{9}{|l|}{ Low dose } \\
\hline Coggins, 2001 [50] & 10 & 0.05 & 240 & $30 \pm 2$ & $24 \pm 1$ & FBF & $\leftrightarrow$ & SGP \\
\hline Fujita, 2006 [76] & 6 & $0.06^{\mathrm{c}}$ & 240 & $29 \pm 3$ & $25 \pm 2$ & LBF & $\uparrow$ & IDM/ICG \\
\hline Coggins, 2001 [50] & 9 & 0.10 & 240 & $23 \pm 1$ & $23 \pm 1$ & FBF & $\uparrow$ & SGP \\
\hline Olsen, 2005 [158] & 6 & 0.17 & 240 & $50 \pm 4$ & $29 \pm 2$ & FBF\&LBF & $\leftrightarrow$ & VUS \\
\hline Timmerman, 2010 [229] & 6 & $0.19^{c}$ & 180 & $74 \pm 3$ & $27 \pm 2$ & LBF & $\leftrightarrow$ & IDM/ICG \\
\hline Fujita, 2006 [76] & 7 & $0.20^{c}$ & 240 & $25 \pm 2$ & $22 \pm 1$ & LBF & $\uparrow$ & IDM/ICG \\
\hline Arcaro, 2002 [10] & 9 & $0.233^{a, b}$ & 360 & $24 \pm 1$ & $22 \pm 1$ & FBF\&LBF & $\downarrow$ & VUS \\
\hline Morgantini, 2012 [141] & 10 & 0.25 & 240 & $27 \pm 1$ & $22 \pm 3$ & FBF & $\leftrightarrow$ & VUS \\
\hline Fujita, 2006 [76] & 6 & $0.40^{c}$ & 240 & $28 \pm 2$ & $26 \pm 2$ & LBF & $\uparrow$ & IDM/ICG \\
\hline Laakso, 1992 [111] & 6 & $0.50^{a}$ & $\mathbf{1 2 0}^{\dagger}$ & $33 \pm 2$ & $22 \pm 1$ & LBF & $\uparrow$ & IDM/thermal \\
\hline \multicolumn{9}{|l|}{ Moderate dose } \\
\hline de Jongh, 2004 [55] & 12 & $0.83^{d}$ & 120 & $27 \pm 8$ & $23 \pm 1$ & LBF & $\uparrow$ & SGP \\
\hline Bonadonna, 1998 [28] & 10 & $0.87^{b}$ & 130 & $19-32$ & $\mathbf{n} / \mathbf{a}$ & FBF & $\leftrightarrow$ & IDM/ICG \\
\hline Scherrer, 1993 [192] & 6 & $0.87^{b}$ & 120 & $29 \pm 4$ & $23 \pm 1$ & LBF & $\uparrow$ & SGP \\
\hline Arcaro, $2002[10]$ & 5 & $0.94^{a, b}$ & 360 & $24 \pm 1$ & $25 \pm 1$ & FBF\&LBF & $\downarrow$ & VUS \\
\hline Eggleston, 2007 [65] & 14 & 1.00 & 120 & $24 \pm 1$ & $23 \pm 1$ & FBF & $\uparrow$ & VUS \\
\hline Clerk, 2006 [47] & 11 & 1.00 & 120 & $37 \pm 3$ & $23 \pm 1$ & FBF & $\uparrow$ & VUS \\
\hline Sonne, 2010 [204] & 20 & $1.08^{a}$ & 120 & $25 \pm 1$ & $24 \pm 1$ & FBF & $\uparrow$ & SGP \\
\hline Nystrom, 2004 [156] & 10 & $1.08^{a}$ & 120 & $29 \pm 4$ & $24 \pm 1$ & FBF & $\leftrightarrow$ & VUS \\
\hline Baron, 1995 [16] & 6 & $1.08^{a}$ & 240 & $35 \pm 2$ & $22 \pm 1$ & LBF & $\uparrow$ & IDM/thermal \\
\hline Laakso, 1992 [111] & 6 & $1.08^{a}$ & $\mathbf{1 2 0}^{\dagger}$ & $33 \pm 2$ & $22 \pm 1$ & LBF & $\uparrow$ & IDM/thermal \\
\hline Cardoso, 2007 [35] & 26 & $1.37^{\mathrm{a}}$ & 120 & $51 \pm 1$ & $25 \pm 1$ & FBF & $\uparrow$ & VUS \\
\hline Hedman, 2001 [88] & 15 & $1.51^{\mathrm{a}}$ & 110 & $70 \pm 2$ & $26 \pm 4$ & LBF & $\leftrightarrow$ & VUS \\
\hline Rosdahl, 1998 [178] & 10 & $1.51^{\mathrm{a}}$ & 120 & 21-32 & $23 \pm 1$ & FBF\&LBF & $\uparrow$ & SGP \\
\hline Tack, 1998 [221] & 13 & $1.62^{a}$ & 120 & $38 \pm 8$ & $22 \pm 1$ & FBF & $\uparrow$ & SGP \\
\hline \multicolumn{9}{|l|}{ High dose } \\
\hline Muniyappa, 2006 [143] & 20 & $3.24^{a}$ & 180 & $40 \pm 3$ & $24 \pm 1$ & FBF & $\uparrow$ & VUS \\
\hline Sjostrand, 2002 [201] & 10 & $3.24^{a}$ & 240 & $40 \pm 4$ & $24 \pm 1$ & FBF & $\uparrow$ & SGP \\
\hline Baron, 1995 [16] & 15 & $3.24^{\mathrm{a}}$ & 240 & $32 \pm 2$ & $22 \pm 1$ & LBF & $\uparrow$ & IDM/thermal \\
\hline Bonadonna, 1998 [28] & 6 & $4.35^{b}$ & 130 & $19-32$ & $\mathbf{n} / \mathbf{a}$ & FBF & $\uparrow$ & IDM/ICG \\
\hline Lteif, 2007 [120] & 9 & $8.11^{a}$ & 240 & $37 \pm 7$ & $22 \pm 3$ & LBF & $\uparrow$ & IDM/thermal \\
\hline Laakso, 1992 [111] & 6 & $8.11^{a}$ & $90^{\dagger}$ & $33 \pm 2$ & $22 \pm 1$ & LBF & $\uparrow$ & IDM/thermal \\
\hline Bonadonna, 1998 [28] & 4 & $8.70^{b}$ & 130 & $19-32$ & $\mathbf{n} / \mathbf{a}$ & FBF & $\uparrow$ & IDM/ICG \\
\hline Baron, 1993 [16] & 19 & $16.22^{\mathrm{a}}$ & 200 & $26 \pm 3$ & $24 \pm 1$ & LBF & $\uparrow$ & IDM/thermal \\
\hline Laakso, 1992 [111] & 6 & $16.22^{\mathrm{a}}$ & $40^{\dagger}$ & $33 \pm 2$ & $22 \pm 1$ & LBF & $\uparrow$ & IDM/thermal \\
\hline
\end{tabular}

Abbreviations: FBF, forearm blood flow; IDM/ICG, indicator dilution method using indocyanine green ; IDM/thermal, indicator dilution method using thermodilution; LBF, leg blood flow; N, number of subjects; N/A, not available; SGP, strain gauge plythesmography; VUS, vascular ultrasound; y, year. (a) Converted from $\left(\mathrm{mU} / \mathrm{m}^{2} / \mathrm{min}\right)$ to $\mathrm{mU} / \mathrm{kg} / \mathrm{min}$. (b) Converting from pmol to $\mathrm{mU}$. (c) Converting from (mU/100ml leg volume/min) to $\mathrm{mU} / \mathrm{kg} / \mathrm{min}$. ${ }^{\text {(d) }}$ Converted from hrs to min. ${ }^{\dagger}$, dose response curve. $\uparrow$, increase. $\downarrow$, decrease. $\leftrightarrow$, no change. 
Table 2. Effects of hyperinsulinemia on conduit vessel blood flow in obese, insulin-resistant individuals.

\begin{tabular}{|c|c|c|c|c|c|c|c|c|c|}
\hline Author & $\mathbf{N}$ & Subject & $\begin{array}{l}\text { Insulin dose } \\
\left(\mathrm{mU} / \mathrm{m}^{2} / \mathrm{min}\right)\end{array}$ & $\begin{array}{c}\text { Duration } \\
\text { (min) }\end{array}$ & Age (y) & $\begin{array}{c}\text { BMI } \\
\left(\mathrm{kg} / \mathrm{m}^{2}\right)\end{array}$ & Endpoint & Outcome & Method \\
\hline \multicolumn{10}{|l|}{ Low dose } \\
\hline Olsen, 2005 [158] & 6 & T2DM & $0.2^{\mathrm{a}}$ & 240 & $58 \pm 2$ & $33 \pm 2$ & FBF\&LBF & $\leftrightarrow$ & VUS \\
\hline Bergdahl, 2009 [189] & 10 & T2DM & $0.3^{\mathrm{a}}$ & 60 & $60 \pm 3$ & $32 \pm 1$ & FBF & $\leftrightarrow$ & SGP \\
\hline \multicolumn{10}{|l|}{ Moderate dose } \\
\hline Clerk, 2006 [47] & 10 & OB/IR & $1.0^{\mathrm{a}}$ & 120 & $43 \pm 2$ & $34 \pm 1$ & FBF & $\leftrightarrow$ & VUS \\
\hline Nystrom, 2004 [156] & 12 & T2DM & 40 & 120 & $61 \pm 3$ & $28 \pm 1$ & FBF & $\leftrightarrow$ & VUS \\
\hline Laakso, 1992 [111] & 6 & OB/T2DM & 40 & $\mathbf{1 8 0}^{\dagger}$ & $40 \pm 1$ & $33 \pm 1$ & LBF & $\leftrightarrow$ & IDM, thermal \\
\hline Laakso, 1990 [110] & 6 & OB/IR & 40 & $\mathbf{1 8 0}^{\dagger}$ & $37 \pm 2$ & $30 \pm 1$ & $\mathbf{L B F}$ & $\uparrow$ & IDM, thermal \\
\hline Tack, 1998 [221] & 15 & OB/IR & 60 & 120 & $37 \pm 5$ & $32 \pm 3$ & FBF & $\leftrightarrow$ & SGP \\
\hline \multicolumn{10}{|l|}{ High dose } \\
\hline Laakso, $1990[110]$ & 6 & OB/IR & 100 & $90^{\dagger}$ & $37 \pm 2$ & $30 \pm 1$ & LBF & $\uparrow$ & IDM, thermal \\
\hline Laakso, 1992 [111] & 6 & OB/T2DM & 120 & $\mathbf{1 8 0}^{\dagger}$ & $40 \pm 1$ & $33 \pm 1$ & LBF & $\leftrightarrow$ & IDM, thermal \\
\hline Muniyappa, 2006 [143] & 20 & OB/IR & 120 & 180 & $49 \pm 3$ & $34 \pm 1$ & FBF & $\uparrow$ & VUS \\
\hline Rennings, 2006 [175] & 18 & OB/IR & 120 & 120 & $46 \pm 9$ & $32 \pm 3$ & FBF & $\leftrightarrow$ & SGP \\
\hline Gudbjornsdottir, 2005 [82] & 8 & T2DM & 120 & 240 & $55 \pm 2$ & $28 \pm 1$ & FBF & $\leftrightarrow$ & SGP \\
\hline Sjostrand, 2002 [201] & 10 & OB/IR & 120 & 240 & $43 \pm 3$ & $32 \pm 1$ & FBF & $\leftrightarrow$ & SGP \\
\hline Lteif, $2007[120]$ & 7 & OB/IR & 300 & 240 & $33 \pm 7$ & $34 \pm 5$ & $\mathbf{L B F}$ & $\uparrow$ & IDM, thermal \\
\hline Laakso, 1992 [111] & 6 & OB/T2DM & 300 & $\mathbf{9 0}^{\dagger}$ & $40 \pm 1$ & $33 \pm 1$ & LBF & $\leftrightarrow$ & IDM, thermal \\
\hline Laakso, 1992 [111] & 6 & OB/T2DM & 600 & $\mathbf{9 0}^{\dagger}$ & $40 \pm 1$ & $33 \pm 1$ & LBF & $\leftrightarrow$ & IDM, thermal \\
\hline Laakso, 1990 [110] & 6 & OB/IR & 600 & $\mathbf{9 0}^{\dagger}$ & $37 \pm 2$ & $30 \pm 1$ & LBF & $\uparrow$ & IDM, thermal \\
\hline Laakso, 1992 [111] & 6 & OB/T2DM & 1200 & $40^{\dagger}$ & $40 \pm 1$ & $33 \pm 1$ & $\mathbf{L B F}$ & $\leftrightarrow$ & IDM, thermal \\
\hline Laakso, 1990 [110] & 6 & OB/IR & 1200 & $\mathbf{4 0}^{\dagger}$ & $37 \pm 2$ & $30 \pm 1$ & LBF & $\uparrow$ & IDM, thermal \\
\hline
\end{tabular}

Abbreviations: FBF, forearm blood flow; IDM/thermal, indicator dilution method using thermodilution; LBF, leg blood flow; N, number of subjects; OB/IR, obese insulin resistant; N, size; SGP, strain gauge plythesmography; T2DM, type 2 diabetes mellitus; VUS, vascular ultrasound; y, year. ${ }^{(a)}$ Dose is in $\mathrm{mU} / \mathrm{kg} / \mathrm{min} .{ }^{\dagger}$, dose response curve. $\uparrow$, increase. $\leftrightarrow$, no change. 
Table 3. Effects of hyperinsulinemia on skeletal muscle microvascular function in lean, healthy and obese, insulin resistant individuals.

\begin{tabular}{|c|c|c|c|c|c|c|c|c|c|}
\hline Author & $\mathbf{N}$ & $\begin{array}{l}\text { Insulin dose } \\
\text { (mU/kg/min) }\end{array}$ & $\begin{array}{c}\text { Duration } \\
\text { (min) }\end{array}$ & Age (y) & BMI $\left(\mathrm{kg} / \mathrm{m}^{2}\right)$ & \multicolumn{3}{|c|}{ Endpoints \& outcome } & Approach \\
\hline \multicolumn{10}{|c|}{ Healthy individuals } \\
\hline Low dose & & & & & & MBV & MBF & MFV & \\
\hline Coggins, 2001 [50] & 10 & 0.05 & 240 & $30 \pm 2$ & $24 \pm 1$ & $\bar{\uparrow}$ & $\mathbf{n} / \mathbf{a}$ & $\downarrow$ & CEU \\
\hline Coggins, 2001 [50] & 9 & 0.10 & 240 & $23 \pm 1$ & $23 \pm 1$ & $\uparrow$ & $\mathbf{n} / \mathbf{a}$ & $\downarrow$ & CEU \\
\hline Timmerman, 2010 [229] & 6 & $0.19^{b}$ & 180 & $74 \pm 3$ & $27 \pm 2$ & $\leftrightarrow$ & $\mathbf{n} / \mathbf{a}$ & $\leftrightarrow$ & CEU \\
\hline \multicolumn{10}{|l|}{ Moderate dose } \\
\hline Mulder, 2008 [142] & 22 & 0.64 & 120 & $22 \pm 4$ & $22 \pm 2$ & $\bar{\uparrow}$ & $\mathbf{n} / \mathbf{a}$ & $\uparrow$ & CEU \\
\hline Chai, 2011 [36] & 11 & 1.00 & 120 & $22 \pm 1$ & $23 \pm 1$ & $\uparrow$ & $\uparrow$ & $\leftrightarrow$ & CEU \\
\hline Meijer, 2012 [135] & 18 & 1.00 & 150 & $31 \pm 11$ & $26 \pm 6$ & $\uparrow$ & $\mathbf{n} / \mathbf{a}$ & $\leftrightarrow$ & CEU \\
\hline Sauder, 2012 [187] & 8 & 1.00 & 120 & $23 \pm 2$ & $23 \pm 1$ & $\uparrow$ & $\uparrow$ & $\leftrightarrow$ & CEU \\
\hline Liu, 2011 [117] & 22 & 1.00 & 120 & $23 \pm 1$ & $23 \pm 1$ & $\uparrow$ & $\uparrow$ & $\downarrow$ & CEU \\
\hline Eggleston, 2007 [65] & 14 & 1.00 & 120 & $24 \pm 1$ & $23 \pm 1$ & $\uparrow$ & $\mathbf{n} / \mathbf{a}$ & $\mathbf{n} / \mathbf{a}$ & CEU \\
\hline Clerk, 2006 [47] & 11 & 1.00 & 120 & $37 \pm 3$ & $23 \pm 1$ & $\uparrow$ & $\mathbf{n} / \mathbf{a}$ & $\leftrightarrow$ & CEU \\
\hline Sjøberg, 2011 [200] & 16 & 1.42 & 60 & $25-28$ & $22-25$ & $\uparrow$ & $\mathbf{n} / \mathbf{a}$ & $\mathbf{n} / \mathbf{a}$ & CEU \\
\hline \multicolumn{10}{|l|}{ High dose } \\
\hline Muniyappa, 2006 [143] & 20 & $3.24^{\mathrm{a}}$ & 180 & $40 \pm 3$ & $24 \pm 1$ & $\uparrow$ & $\mathbf{n} / \mathbf{a}$ & $\uparrow$ & CEU \\
\hline Sjøberg, 2011 [200] & 16 & 5.00 & 60 & $25-28$ & $22-25$ & $\uparrow$ & $\mathbf{n} / \mathbf{a}$ & $\mathbf{n} / \mathbf{a}$ & CEU \\
\hline Murdolo, 2008 [145] & 8 & $23.76^{\mathrm{c}}$ & 240 & $46 \pm 3$ & $31 \pm 1$ & $\uparrow$ & $\mathbf{n} / \mathbf{a}$ & $\mathbf{n} / \mathbf{a}$ & Microdialysis \\
\hline
\end{tabular}

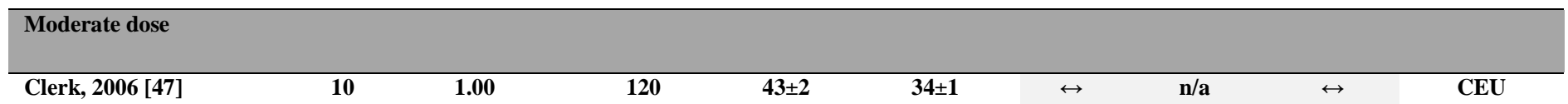

\begin{tabular}{|c|c|c|c|c|c|c|c|c|c|}
\hline \multicolumn{10}{|l|}{ High dose } \\
\hline Muniyappa, 2006 [143] & 20 & $120.0^{*}$ & 180 & $49 \pm 3$ & $34 \pm 1$ & $\uparrow$ & $\mathbf{n} / \mathbf{a}$ & $\uparrow$ & CEU \\
\hline Murdolo, 2008 [145] & 7 & $22.02^{c}$ & 240 & $46 \pm 5$ & $32 \pm 1$ & $\uparrow$ & $\mathbf{n} / \mathbf{a}$ & $\mathbf{n} / \mathbf{a}$ & Microdialysis \\
\hline
\end{tabular}

Abbreviations: CEU, contrast enhanced ultrasound; LDU, laser Doppler ultrasound; MBF, microvascular blood flow, MBV, microvascular blood volume, MFV, microvascular flow velocity. ${ }^{\text {(a) }}$ Converted from (mU/m²/min) to $\mathrm{mU} / \mathrm{kg} / \mathrm{min}$. (b) $\mathrm{Converting}$ from (mU/100ml leg volume/min) to $\mathrm{mU} / \mathrm{kg} / \mathrm{min}$. ${ }^{(\mathrm{c})}$ Converting from $\mathrm{mg} / \mathrm{min}$ to $\mathrm{mU} / \mathrm{kg}$ assuming $1 \mathrm{mg}$ of insulin contains $24 \mathrm{mU}$ and the average weight was $101 \mathrm{~kg}$ for healthy subjects and $109 \mathrm{~kg}$ for obese insulin-resistant subjects. ${ }^{*}$, dose is in $\mathrm{mU} / \mathrm{m}^{2} / \mathrm{min} .($ equivalent to $3.24 \mathrm{mU} / \mathrm{kg} / \mathrm{min}$ in lean subjects). $\uparrow$, increase. $\downarrow$, decrease. $\leftrightarrow$, no change 


\section{FIGURE LEGENDS}

Fig 1. Physiological action of insulin on the peripheral vascular tree of skeletal muscle. Insulin causes relaxation of large conduit arteries, terminal resistance arterioles and capillaries in skeletal muscle resulting in increases in blood flow, capillary perfusion and capillary recruitment, respectively.

Fig 2. Insulin's vasoregulatory signaling pathway under normal physiological conditions. Summary of the signaling pathway by which insulin induces vasodilation. Binding of insulin to the insulin receptor is followed by activation of PI3K and subsequently AKT, which phosphorylates eNOS and increases the production of NO. NO diffuses to adjacent smooth muscle cells and promotes smooth muscle cell relaxation leading to vasodilation. Binding of insulin to the insulin receptor initiates activation of RAS/RAF, which subsequently induces activation of MEK and ERK1/2 leading to increased production of ET-1. ET-1 binds to the ET receptor type A on the surface of adjacent smooth muscle cells promoting their contraction leading to vasoconstriction. eNOS, endothelial nitric oxide synthase; ERK, extracellular signal-regulated kinase; ET-1, endothelin-1; MEK, mitogen activated or extracellular protein kinase kinase; NO, nitric oxide; $P I 3 K$, phosphatidylinositol 3 kinase; RAF, rapidly accelerated fibrosarcoma; RAS, rat sarcoma.

Fig 3. ET-1 receptor-mediated actions on endothelial cells and vascular smooth muscle cells. ET-1 binds to ET $\mathrm{B}_{\mathrm{B}}$ receptors on the surface of endothelial cells and activates the PI3/AKT pathway which induces eNOS activity and NO production. NO diffuses to the neighboring smooth muscle cells and activates the GC enzyme that transforms GTP to C-GMP resulting in a reduction of intracellular $\mathrm{Ca}^{2+}$ levels and vasodilation. ET-1 binds to $\mathrm{ET}_{\mathrm{A}}$ or $\mathrm{ET}_{\mathrm{B} 2}$ receptors on the surface of smooth muscle cells activates the PLC/IP3 pathway which, in turn, increases intracellular $\mathrm{Ca}^{2+}$ levels and activates the PKC pathway resulting in cell contraction and vasoconstriction. $A K T$, protein kinase B; C-GMP, cyclic guanosine monophosphate; eNOS, endothelial nitric oxide synthase; ET-1, endothelin-1; ET $A$, endothelin receptor type A; $E T_{B 1}$, endothelin receptor type B1; $E T_{B 2}$, endothelin receptor type B2, GC, guanylate cyclase; GTP, Guanosine triphosphate; IP3,inositol triphosphate; MAPK, mitogen activated protein kinase; NO, nitric oxide; PI3K, phosphatidyl insositol 3 kinase; PLC, phospholipase C; RAF, rapidly accelerating fibrosarcoma.

Fig 4. Counterbalance of insulin action through MAPK/ET-1 and PI3K/NO signaling axes. Insulin sensitivity preserves the balance between vasoconstrictive (MAPK/ET-1) and vasodilatory (PI3K/NO) pathways downstream of the insulin receptor. With insulin resistance and compensatory hyperinsulinemia, the PI3K/NO axis is compromised leading to an unopposed vasoconstrictive action of MAPK/ET-1 pathway. ET-1, endothelin-1; MAPK, mitogen activated protein kinase; $N O$, nitric oxide; PI3K, phosphatidylinositol 3 kinase.

Fig 5. Vascular dysfunction caused by hyperinsulinemia-induced ET-1 production. Schematic illustration of the hyperinsulinemia mediated enhancement of ET-1 production and the subsequent deleterious actions on vascular endothelial cells and smooth muscle cells. COX, Cyclooxygenase; DAG, Diacylglycerol; ET-1, endothelin-1; GRB2, Growth Factor ReceptorBound Protein-2; ICAMs, Inter-Cellular Adhesion Molecules; IFN, Interferon; IL, Interleukin; IP3, Inositol 1,4,5 triphosphate; MAPK, Mitogen Activated Protein Kinase; PAF, Platelet Activating Factor; PAI, plasminogen Activator Inhibitor; PLA2, Phospholipase A2; PLC, Phospholipase-C; PLD, Phospholipase D; TNF, Tumor Necrosis Factor; TX, Thromboxane; VCAMs, Vascular Cell Adhesion Molecules; vWF, von Willebrand Factor. 


\section{FIGURES}

Figure 1

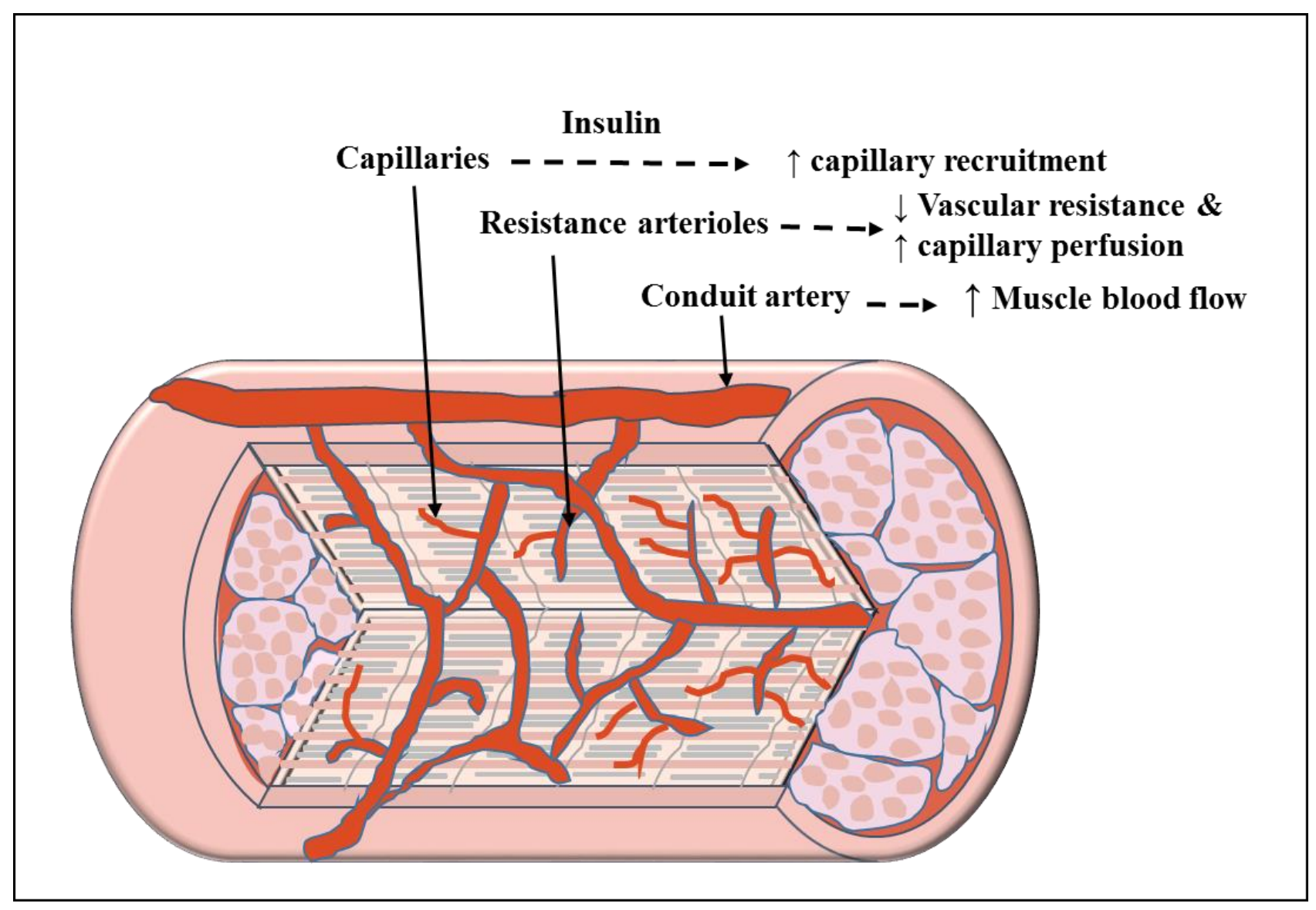


Figure 2

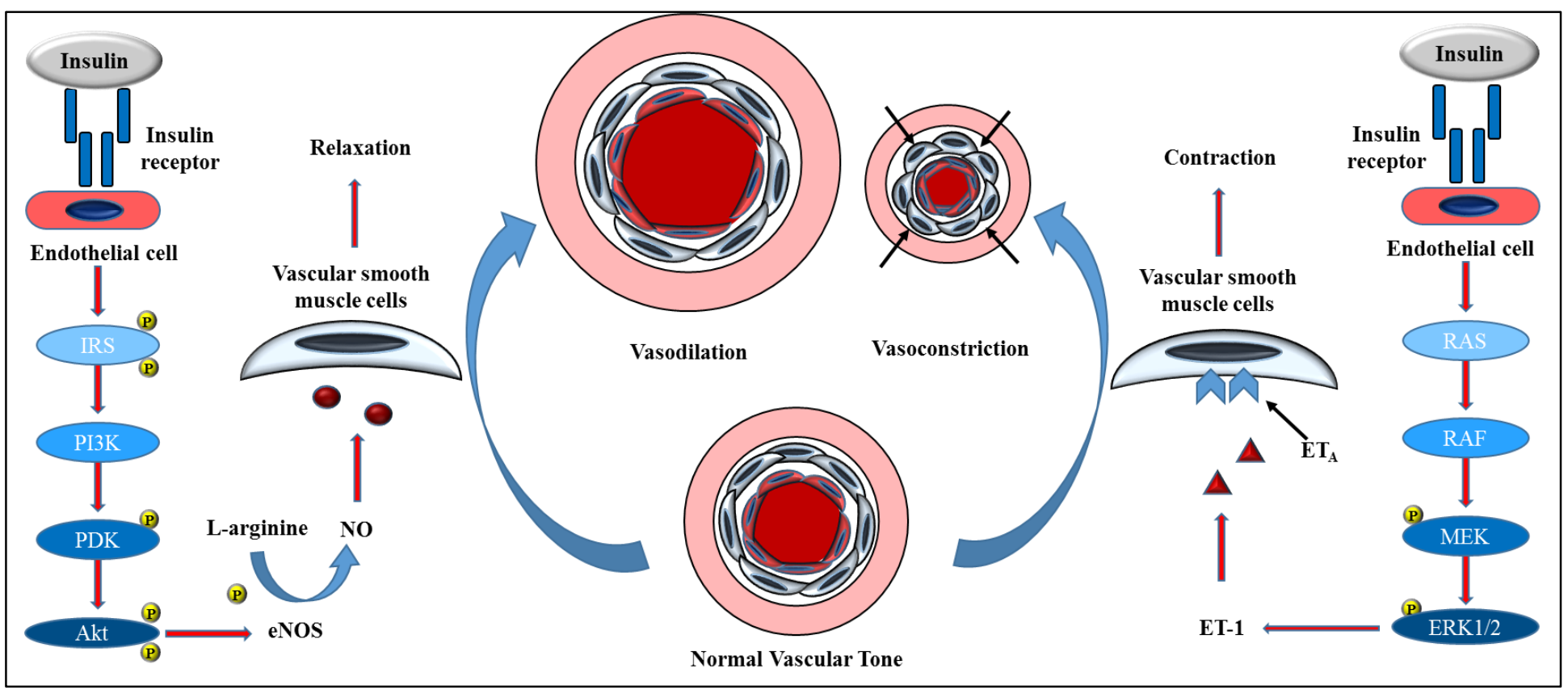


Figure 3

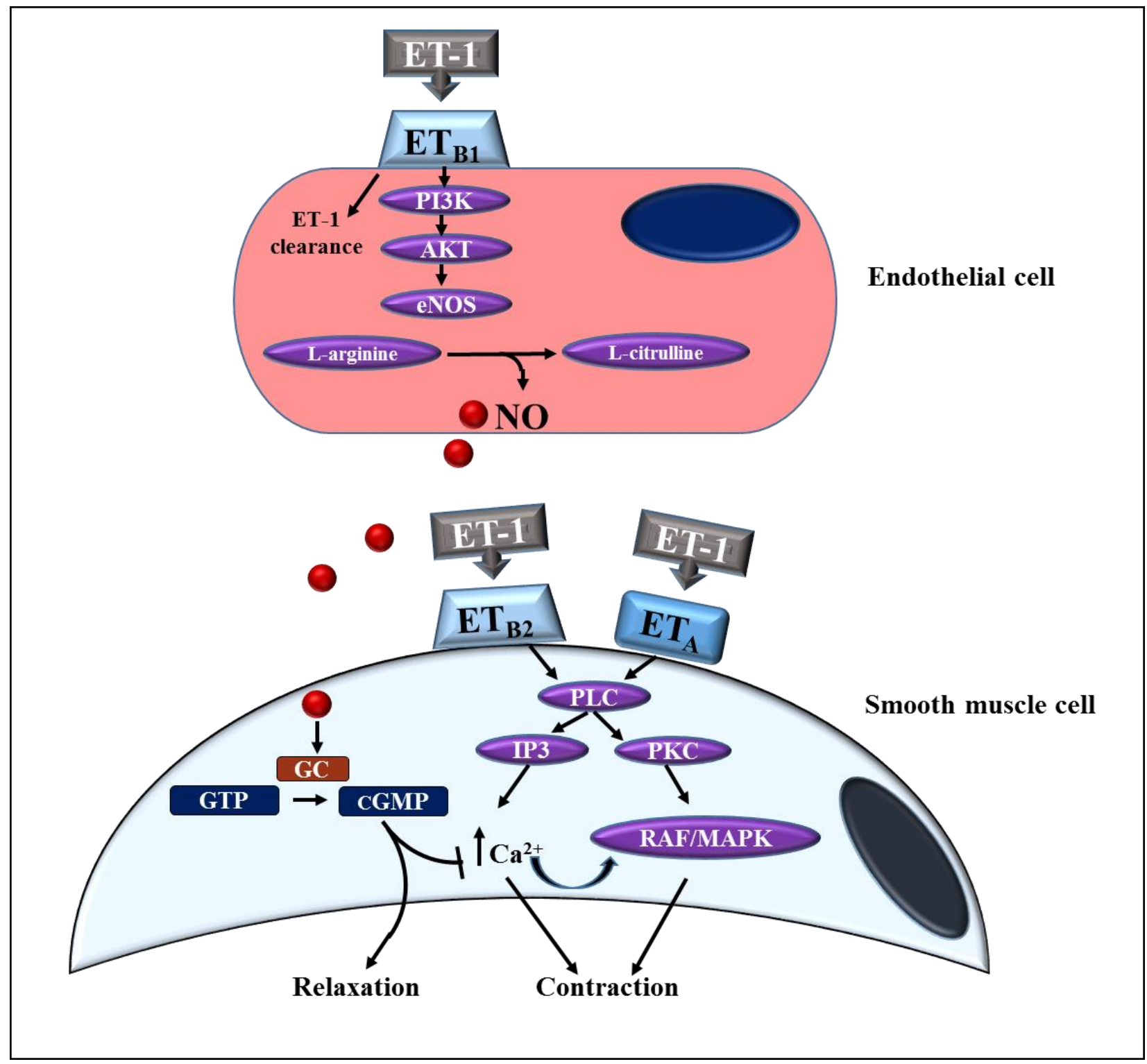


Figure 4

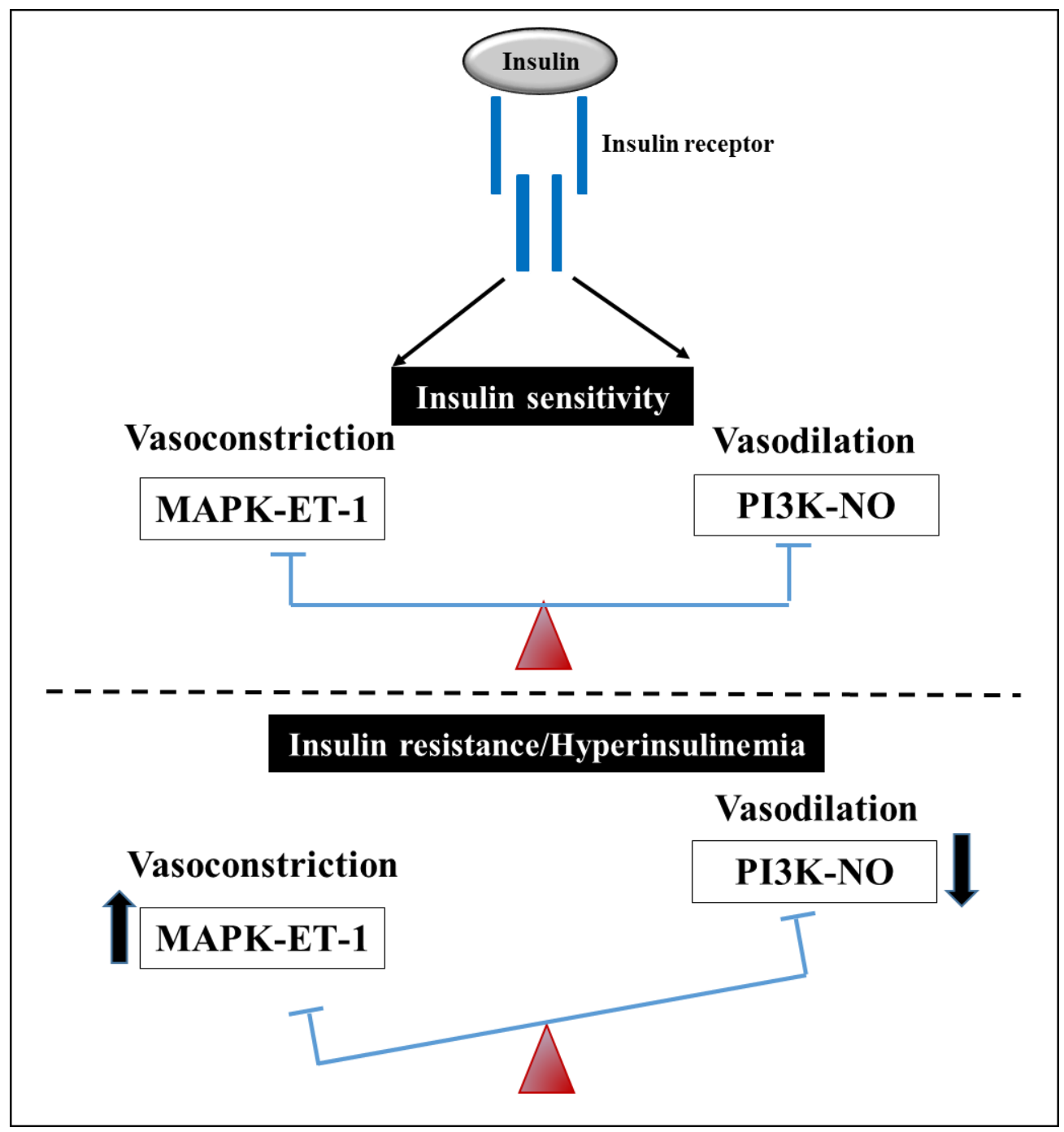


Figure 5

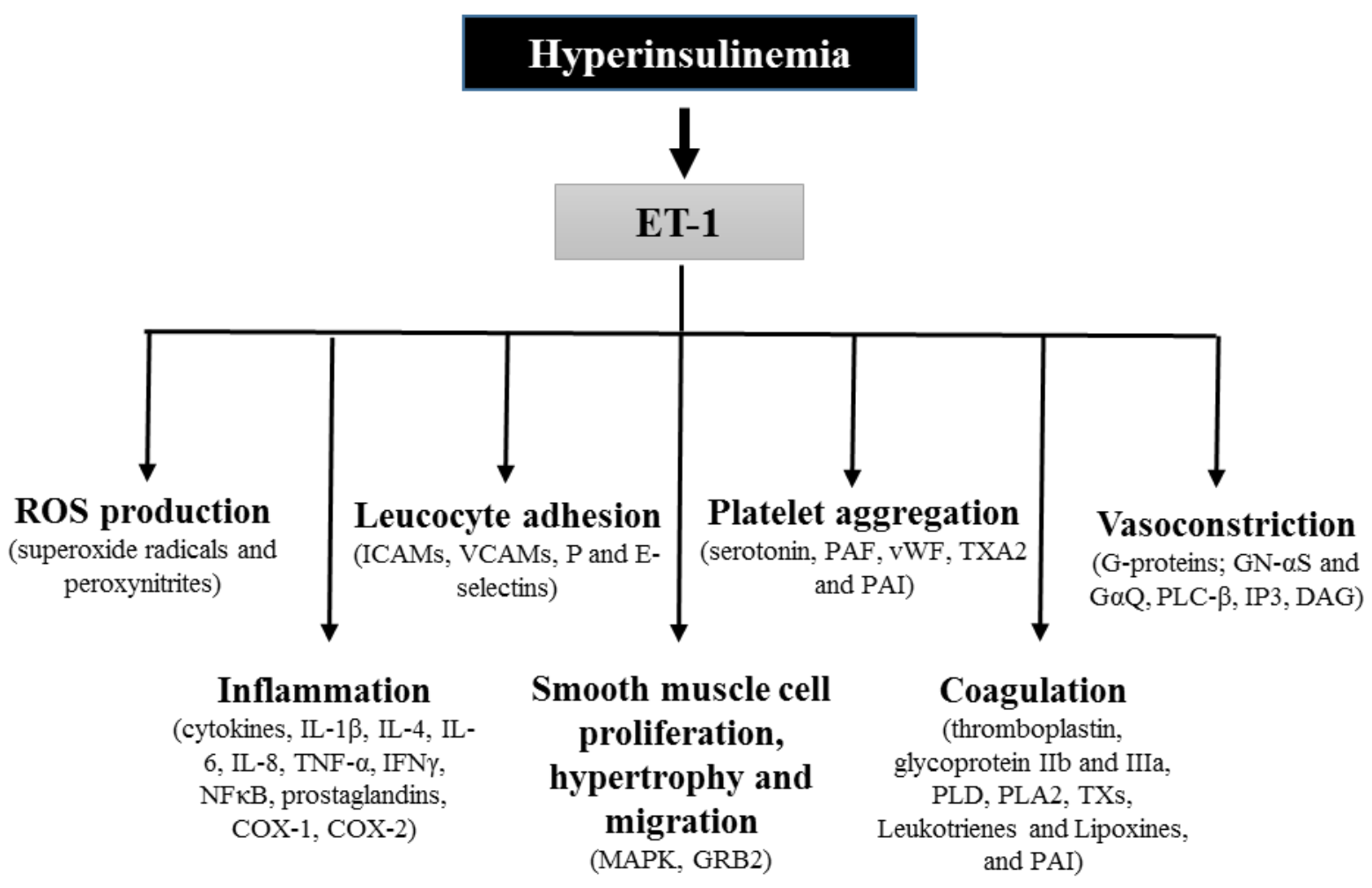

